\title{
Article \\ Computational Model Development for Hybrid Tilting Pad Journal Bearings Lubricated with Supercritical Carbon Dioxide
}

\author{
Syed Muntazir Mehdi ${ }^{1}$ and Tae Ho Kim ${ }^{2, *}$ (1) \\ 1 Department of Mechanics and Design, Kookmin University, Seoul 02707, Korea; munte07@kookmin.ac.kr \\ 2 School of Mechanical Engineering, Kookmin University, Seoul 02707, Korea \\ * Correspondence: thk@kookmin.ac.kr
}

Featured Application: Power generation systems based on supercritical carbon dioxide.

check for updates

Citation: Mehdi, S.M.; Kim, T.H. Computational Model Development for Hybrid Tilting Pad Journal

Bearings Lubricated with

Supercritical Carbon Dioxide. Appl. Sci. 2022, 12, 1320. https://doi.org/ 10.3390/app12031320

Academic Editor: Homer Rahnejat

Received: 19 November 2021

Accepted: 21 January 2022

Published: 26 January 2022

Publisher's Note: MDPI stays neutral with regard to jurisdictional claims in published maps and institutional affiliations.

Copyright: (C) 2022 by the authors. Licensee MDPI, Basel, Switzerland. This article is an open access article distributed under the terms and conditions of the Creative Commons Attribution (CC BY) license (https:// creativecommons.org/licenses/by/ $4.0 /)$.

\begin{abstract}
Fluid film bearings lubricated with supercritical carbon dioxide $\left(\mathrm{sCO}_{2}\right)$ eliminate the infrastructural requirement for oil lubricant supply and sealing in turbomachinery for $\mathrm{sCO}_{2}$ power systems. However, $\mathrm{sCO}_{2}$ 's thermohydrodynamic properties, which depend on pressure and temperature, pose a challenge, particularly with computational model development for such bearings. This study develops a computational model for analyzing $\mathrm{sCO}_{2}$-lubricated tilting pad journal bearings (TPJBs) with external pressurization. Treating $\mathrm{sCO}_{2}$ as a real gas, the Reynolds equation for compressible turbulent flows solves the pressure distribution using the finite element method, and the Newton-Raphson method determines the static equilibrium position by simultaneously calculating forces, moments, flow rates of externally pressurized $\mathrm{sCO}_{2}$, and pressure drop due to flow inertia. The finite difference method solves the energy equation for temperature distribution. The density and viscosity of $\mathrm{sCO}_{2}$ are converged using the successive substitution method. The obtained predictions agree with the previous and authors' computational fluid dynamics predictions, thus validating the developed model. Hybrid lubrication increases the minimum film thickness and stiffness up to $80 \%$ and $65 \%$, respectively, and decreases the eccentricity ratio by up to $65 \%$ compared to those of pure hydrodynamic TPJB, indicating significant improvement in the load capacity. The bearing performance is further improved with increasing $\mathrm{sCO}_{2}$ supply pressure.
\end{abstract}

Keywords: tilting-pad journal bearing; hybrid lubrication; supercritical carbon dioxide; load capacity

\section{Introduction}

The supercritical carbon dioxide $\left(\mathrm{sCO}_{2}\right)$ cycle enables higher thermal efficiency than the conventional steam Rankine cycle, resulting in reduced fuel cost and greenhouse gas production [1]. Thus, the $\mathrm{sCO}_{2}$ cycle is extensively applied in various power-conversion systems, including concentrated solar thermal and nuclear power [2-5], waste heat recovery from large engines [6], and geothermal [1].

The high density of $\mathrm{sCO}_{2}$ at high-pressure can cause compact turbomachinery, critical equipment in circulatory systems for the $\mathrm{sCO}_{2}$ thermodynamic cycle, at low capital costs [2] To achieve commercial viability, various types of bearings have been investigated to support the rotors of such high-speed turbomachinery.

Wright et al. [2] replaced angular contact ball bearings initially installed in a turbocompressor for the $\mathrm{sCO}_{2}$ Brayton cycle with gas-foil bearings (GFBs). The GFBs lubricated with $\mathrm{sCO}_{2}$, enabled a simple configuration without the sealing mechanism to prevent oil contamination and ensured a long bearing life. During preliminary tests, the authors found that high-pressure $\mathrm{sCO}_{2}$ in the foil thrust bearing generates significant power loss, which is attributed to the rotational speed. Cho et al. [7] employed GFBs to support the shaft in their 10-kWe-class unrecuperated $\mathrm{sCO}_{2}$ Brayton cycle [7]. Preliminary operations were successfully conducted at $30 \mathrm{krpm}$ and at a turbine inlet temperature and pressure of $83{ }^{\circ} \mathrm{C}$ 
and $8500 \mathrm{kPa}$, respectively. Cho et al. [8] also reported a 60-kWe-class recuperated Brayton cycle facility with turbomachinery supported on oil-lubricated tilting-pad bearings. To prevent oil contamination of the process fluid $\left(\mathrm{sCO}_{2}\right)$, carbon ring-type mechanical seals are fixed between the turbine and the bearing unit, resulting in a long shaft. The above-cited studies focused on cycle analysis rather than the constituents. Although Ahn et al. [9] and Utamura et al. [10] studied the design of the experimental loop for $\mathrm{sCO}_{2}$ power cycles, they did not detail the bearings employed for turbomachinery.

To achieve the desired performance of turbomachinery for $\mathrm{sCO}_{2}$ power cycles, the performance of their bearings is an important design consideration [10]. Thus, researchers have developed computational models to predict the performance of various types of $\mathrm{sCO}_{2}-$ lubricated bearings. Conboy [11] used an isothermal and real gas model to investigate the static performance of a $\mathrm{SCO}_{2}$-lubricated gas-foil thrust bearing (GFTB). The author used the thermodynamic properties of $\mathrm{sCO}_{2}$ reported in Ref. [12] and showed that GFTB has a larger load capacity and power loss when lubricated with $\mathrm{sCO}_{2}$ than with air. Qin et al. [13,14] investigated the static performance of $\mathrm{sCO}_{2}$-lubricated GFTBs using computational fluid dynamics (CFD). Dousti and Allaire [15] studied a plain $\mathrm{sCO}_{2}$-lubricated journal bearing using a density model linearized with pressure. The isothermal model considers pressuredependent density on only the Reynolds equation's left-hand side (Poiseuille terms). The overly simplified compressible model predicted a greater load capacity of the bearing than did the incompressible model. Heshmat et al. [16] assumed $\mathrm{sCO}_{2}$ as an isothermal ideal gas and analyzed a gas-foil journal bearing (GFJB) with the same diameter and length as the journal bearing reported in Ref. [15]. The authors predicted a comparable load capacity of GFJB for the plain journal bearing. In addition, they reported that the load capacity obtained using the compressible model is higher than that obtained using the incompressible model, which is inconsistent with the results reported in Ref. [15]. Dimond and Allaire [17] studied $\mathrm{sCO}_{2}$-lubricated tilting pad journal bearings (TPJBs). The predictive model neglects the most crucial parameters associated with $\mathrm{sCO}_{2}$, such as the density and viscosity dependency on pressure and temperature. The authors compared oil- and $\mathrm{sCO}_{2-}$ lubricated TPJBs and discovered that using $\mathrm{sCO}_{2}$ as a TPJB lubricant requires increased bearing size to have dynamic coefficients comparable to those of oil-lubricated TPJBs. $\mathrm{Xu}$ and Kim [18] developed a thermoelastohydrodynamic model for $\mathrm{CO}_{2}$-lubricated externally pressurized GFTB. The lubricant, $\mathrm{CO}_{2}$, was treated as a real gas. The authors compared laminar and turbulent flow models for $\mathrm{CO}_{2}$ - and R245fa-lubricated bearings. Preuss [19] analyzed hybrid journal and thrust bearings lubricated with $\mathrm{sCO}_{2}$ and calculated the load capacity using the rule of thumb. To calculate the rotordynamic coefficients, the author used a commercial tool developed by San Andres and Childs [20] for water-lubricated journal bearings and reported that the stiffness coefficient increases with an increase in the bearing diameter for angled injection hybrid journal bearing. Chunxiao et al. [21] reported a detailed dynamic analysis of $\mathrm{sCO}_{2}$-lubricated plain journal bearings. The turbulent flow model employs the look-up table method to extract the thermodynamic properties of $\mathrm{sCO}_{2}$ in Ref. [12], similar to that in Ref. [11]. Kim et al. [22] conducted theoretical and experimental studies on the rotor dynamic instability of magnetic journal bearings operating in an $\mathrm{sCO}_{2}$ ambiance. To understand the unstable shaft levitation at high speeds, $\mathrm{sCO}_{2}$ pressure forces developed between the shaft and the magnetic bearings were calculated using the one-dimensional Reynolds equation.

Herein, we developed a computational model for hybrid (hydrostatic/hydrodynamic) TPJB lubricated with $\mathrm{sCO}_{2}$ and predict its static and dynamic performances. In the hybrid TPJB, pressurized $\mathrm{sCO}_{2}$ is supplied through a hole located at the center of the pad's recess to enhance the load capacity and dynamic characteristics, as reported for water- and airlubricated bearings $[20,23,24]$. The Reynolds equation for turbulent compressible fluid flows solves hydrodynamic pressure generation. The mass flow balance between the orifice flow and the Poiseuille and Couette flows at the pad recess boundaries calculates the recess pressure. The fluid inertia effects at the recess boundaries, which cause a pressure drop, 
were modeled using the average velocities of film flows. The real gas model is used for $\mathrm{sCO}_{2}$, whose thermophysical properties are functions of pressure and temperature.

\section{Hybrid TPJB Lubricated with $\mathrm{sCO}_{2}$ and Its Computational Model}

Figure 1 shows a schematic of TPJB with four pads and an angular extent of $\theta_{\text {pad }}$ in the load-between-pad (LBP) configuration. Each pad has a rectangular recess with a hole at its geometric center to supply pressurized $\mathrm{sCO}_{2}$ through the pivot support. The supplied $\mathrm{sCO}_{2}$ flows into the gap between the rotating journal and the pads.

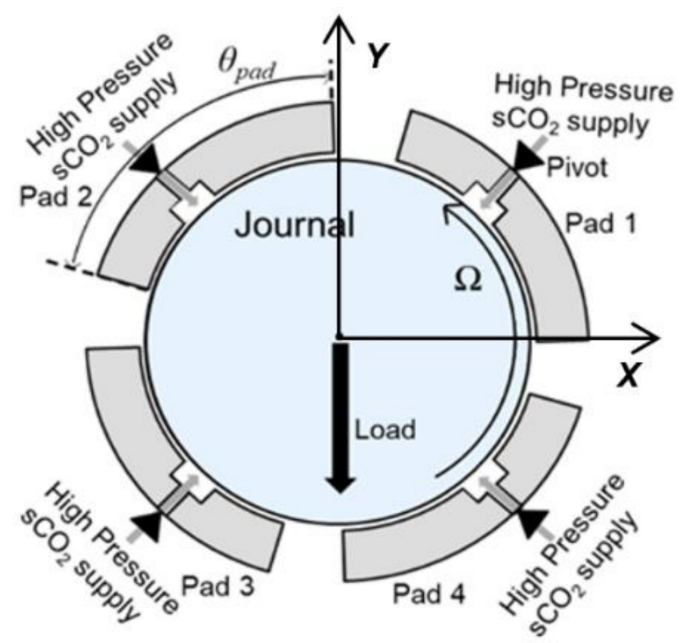

Figure 1. Schematic of a four-pad tilting-pad journal bearing (TPJB) in a load-between-pad (LBP) configuration with recesses for high-pressure supercritical carbon dioxide $\left(\mathrm{sCO}_{2}\right)$ supply.

\subsection{Thermohydrodynamic Model for Turbulent Compressible Fluid Flows}

The Reynolds equation for turbulent and compressible fluid flows governs pressure distribution in the film land area. Note that $\mathrm{sCO}_{2}$ is a highly compressible fluid, and its large density and low viscosity result in a large Reynolds number:

$$
\frac{\partial}{\partial x}\left(\frac{G_{x} \rho h^{3}}{\mu} \frac{\partial p}{\partial x}\right)+\frac{\partial}{\partial z}\left(\frac{G_{z} \rho h^{3}}{\mu} \frac{\partial p}{\partial z}\right)=\frac{U}{2} \frac{\partial(\rho h)}{\partial x}+\frac{\partial(\rho h)}{\partial t}
$$

where $\rho, h, \mu, p, U, t, x$, and $z$ denote the lubricant density, film thickness, viscosity, pressure, journal surface speed, time, circumferential coordinate, and axial coordinate, respectively. $G_{x}$ and $G_{z}$ are the turbulent coefficients empirically determined using the Hirs bulk flow model [25], which considers the inertia effects inherent to the flow turbulence:

$$
G_{x}=\frac{1}{2+m_{0}} G_{z}, G_{z}=\frac{2^{1+m_{0}}}{n_{0}} R e^{-\left(1+m_{0}\right)}
$$

where $m_{0}(=-0.25)$ and $n_{0}(=0.066)$ are empirical constants applicable exclusively to smooth surfaces. Re is the local flow Reynolds number dependent on the local density $\rho$, viscosity $\mu$, and film thickness $h$ :

$$
R e=\frac{\rho U h}{\mu}
$$

The flow becomes turbulent when $R e$ is greater than or equal to the critical Reynolds number $R e_{c}$, which is equal to $1000[15,26,27]$. For $R e$ less than the critical value, $G_{x}$ and $G_{z}$ are equal to $1 / 12$ for the laminar flow.

The equation of film thickness is modified from that in Ref. [28] by including the recess depth $D_{r}$ to account for the depth of the recess:

$$
h=C_{p}+e \cos \left(\theta_{c}-\theta\right)-\left(r_{p}-\zeta\right) \cos \left(\theta-\theta_{p}\right)-\delta\left(R_{p}+t_{p}\right) \sin \left(\theta-\theta_{p}\right)+D_{r}
$$


where $C_{p}\left(=R_{p}-R_{j}\right), e, \theta_{c}, \theta, r_{p}\left(=R_{p}-R_{b}\right), \zeta, \theta_{p}, \delta, t_{p}$, and $D_{r}$ are the pad radial clearance, journal eccentricity, angle between the line passing through the bearing and journal centers and the horizontal axis $X$, circumferential coordinate starting from the axis $X$, preload, pivot deflection, pivot circumferential location, pad tilt angle, pad thickness, and depth of the recess, respectively. $R_{p}, R_{b}$, and $R_{j}$ are the pad, bearing, and journal radii, respectively. The mathematical model for the pivot deflection $\zeta$ is detailed in Refs. [28-30]. Note that $D_{r}$ is null at the film land region.

In the recess region, externally pressurized $\mathrm{sCO}_{2}$ with pressure $p_{s}$ is provided through the orifice restrictor, causing a pressure drop from $p_{s}$ to $p_{r e}$, which then flows over the land area on each pad's surface. The gaseous mass flow rate through the orifice restrictor $Q_{0}$ for the choked and unchoked conditions are derived from the Bernoulli's equation considering mechanical energy balance between two arbitrary points on a streamline. The relations for both choked and unchoked conditions can be given from [18,31] as follows:

$$
\begin{aligned}
& \text { Un - choked }: \frac{p_{r e}}{p_{s}}>\left(\frac{2}{\kappa+1}\right)^{\kappa /(\kappa-1)} \\
& Q_{o}=C_{d} A_{o} \sqrt{R_{g} T_{s}} \sqrt{\frac{2 \kappa}{\kappa-1}\left[\left(\frac{p_{r e}}{p_{s}}\right)^{2 / \kappa}-\left(\frac{p_{r e}}{p_{s}}\right)^{(\kappa+1) / \kappa}\right]} \\
& \text { Choked }: \frac{p_{r e}}{p_{s}} \leq\left(\frac{2}{\kappa+1}\right)^{\kappa /(\kappa-1)} \\
& Q_{o}=C_{d} A_{o} \sqrt{R_{g} T_{s}} \sqrt{\frac{2 \kappa}{\kappa+1}}\left(\frac{2}{\kappa+1}\right)^{1 /(\kappa-1)}
\end{aligned}
$$

where $C_{d}, A_{o}, R_{g}$, and $T_{s}$ are the discharge coefficient, orifice area, gas constant, and supply temperature, respectively, and $\kappa$ is the ratio of the specific heat capacity at constant pressure $c_{p}$ to that at constant volume $c_{v}$.

The mass flow balance between the orifice mass flow $\left(M_{o}=\rho Q_{o}\right)$ and Poiseuille and Couette flows at the recess's circumferential leading $\left(\Gamma_{i}\right)$ and trailing $\left(\Gamma_{i^{\prime}}\right)$ boundaries and axial leading $\left(\Gamma_{j}\right)$ and trailing $\left(\Gamma_{j^{\prime}}\right)$ boundaries gives recess pressure $\left(p_{r e}\right)$ :

$$
\int_{\Gamma_{i} \cup \Gamma_{i^{\prime}}}\left(\frac{G_{x} \rho h^{3}}{\mu} \frac{\partial p}{\partial x}-\frac{\rho U h}{2}\right) d z+\int_{\Gamma_{j} \cup \Gamma_{j^{\prime}}}\left(\frac{G_{z} \rho h^{3}}{\mu} \frac{\partial p}{\partial z}\right) d x=M_{o}
$$

The pressure drop due to inertia forces at the boundary edges of the recess is modeled based on Bernoulli type relationships [32,33]. These relationships were derived for step bearings by assuming inertia effect dependency on average velocity instead of local velocity. The equations for turbulent flows can be given as follows:

Circumferential direction:

$$
\begin{aligned}
p_{r e}-p_{d c}= & \frac{\rho}{2} Q_{l}{ }^{2}\left(\frac{1}{h_{l}{ }^{2}}-\frac{1}{h_{r r^{2}}}\right)+0.412 \rho Q_{l}{ }^{2}\left(\frac{\delta_{l}}{h_{l}{ }^{2}}-\frac{\delta_{r e}}{h_{r e}{ }^{2}}\right)-1.725 \rho V^{2}\left(\beta_{l}-\beta_{r e}\right) \\
& \text { where } \beta=\frac{0.885}{R e^{0.367}}, \delta=\frac{1.95}{R^{0} 0^{4.43}} \quad l: \text { film land, re: recess }
\end{aligned}
$$

Axial direction:

$$
p_{r e}-p_{d a}=\frac{\rho}{2} Q_{l}{ }^{2}\left(\frac{1}{h_{l}{ }^{2}}-\frac{1}{h_{r e}{ }^{2}}\right)
$$

where $p_{d c}$ and $p_{d a}$ are the pressures at the entrances of the film land in the circumferential and axial directions, respectively. $Q_{l}, h_{l}$, and $h_{r e}$ are the flux, film thickness at the land area, and film thickness at the recess area, respectively.

The numerical scheme to find the recess pressure $\left(p_{r e}\right)$ and pressure drops $\left(p_{r e}-p_{d c}\right.$, $\left.p_{r e}-p_{d a}\right)$ at the entrance boundary of the film land for a given supply pressure $\left(p_{s}\right)$ is explained in the next section.

The energy equation calculates the temperature distribution $T$. In the energy equation, thermal energy transport due to fluid flow advection and heat convection into the bearing 
and journal surfaces balance the compression work and frictional power dissipation as follows [34]:

$$
\begin{aligned}
& c_{p}\left[\frac{\partial(\rho h V T)}{\partial x}+\frac{\partial(\rho h W T)}{\partial z}\right]+h_{t b}\left(T-T_{b}\right)+h_{t j}\left(T-T_{j}\right)=\beta_{t} h T\left[V \frac{\partial p}{\partial x}+W \frac{\partial p}{\partial z}\right]+\frac{h u}{2} \frac{\partial p}{\partial x} \\
& +\frac{\mu}{h}\left[\frac{1}{G_{x}}\left(V^{2}+W^{2}+\frac{U}{2} V\right)+\frac{U}{G_{x}}\left(\frac{U}{4}-V\right)\right]
\end{aligned}
$$

where $V$ and $W$ are the bulk flow velocities in the circumferential and axial directions, respectively, and $h_{t b}$ and $h_{t j}$ are the convective heat transfer coefficients for the bearing surface at temperature $T_{b}$ and journal at temperature $T_{j}$, respectively. $\beta_{t}$ is the volumetric expansion coefficient [34], which can be calculated using the following relation:

$$
\beta_{t}=-\left(\frac{1}{\rho} \frac{\partial \rho}{\partial T}\right)_{\rho}
$$

Notably, $\beta_{t}$ is 0 for incompressible liquids and 1 for ideal gases. The thermal energy mixing model for the inlet flow between adjacent pads follows Ref. [28].

\subsection{Real Gas Model for $\mathrm{sCO}_{2}$}

$\mathrm{CO}_{2}$ is a real gas whose density and viscosity vary with temperature and pressure, particularly in the supercritical region. Therefore, the current study takes the density and viscosity models proposed by Wang et al. [35] and Fenghour and Wakeham [36], respectively, to predict the pressure and temperature-dependent density and viscosity of $\mathrm{CO}_{2}$.

The empirical model for calculating the density of $\mathrm{CO}_{2}$ is valid for pressure and temperature ranging from 3 to $60 \mathrm{MPa}$ and from 303 to $473 \mathrm{~K}$, respectively. The density can be expressed as follows:

$$
\begin{aligned}
& \rho=\left(a_{1} T_{r}^{3}+a_{2} T_{r}^{2}+a_{3} T_{r}+a_{4}\right) p_{r}{ }^{6}+\left(b_{1} T_{r}^{3}+b_{2} T_{r}^{2}+b_{3} T_{r}+b_{4}\right) p_{r}{ }^{5}+\left(c_{1} T_{r}{ }^{3}+c_{2} T_{r}{ }^{2}+c_{3} T_{r}+c_{4}\right) p_{r}{ }^{4} \\
& +\left(d_{1} T_{r}{ }^{3}+d_{2} T_{r}{ }^{2}+d_{3} T_{r}+d_{4}\right) p_{r}{ }^{3}+\left(e_{1} T_{r}^{3}+e_{2} T_{r}{ }^{2}+e_{3} T_{r}+e_{4}\right) p_{r}{ }^{2}+\left(f_{1} T_{r}{ }^{3}+f_{2} T_{r}{ }^{2}+f_{3} T_{r}+f_{4}\right) p_{r} \\
& +\left(g_{1} T_{r}{ }^{3}+g_{2} T_{r}{ }^{2}+g_{3} T_{r}+g_{4}\right)
\end{aligned}
$$

where $T_{r}\left(=T / T_{c}\right)$ and $p_{r}\left(=p / p_{c}\right)$ are the ratios of the local temperature and pressure to the temperature and pressure at the critical point of $\mathrm{CO}_{2}$, respectively. Note that $T_{c}=304.1 \mathrm{~K}$, and $p_{c}=7.37 \mathrm{MPa}$. See Ref. [35] for the values of the coefficients $\left(a_{i}, \ldots, g_{i}, i=1, \ldots, 4\right)$. Note that the value of c4 is mistyped in Ref. [35] and the correct value is - 23259.58953 [15].

The viscosity equation is also empirically derived, which models $\mathrm{CO}_{2}$ as a function of temperature and density:

$$
\begin{gathered}
\mu=\frac{1.00697 \sqrt{T}}{G^{*}\left(T^{*}\right)}+l_{11} \rho+l_{21} \rho^{2}+\frac{l_{61} \rho^{6}}{T^{* 3}}+l_{81} \rho^{8}+\frac{l_{82} \rho^{8}}{T^{*}} \\
\ln G^{*}\left(T^{*}\right)=\sum_{n=0}^{4} \lambda_{n}\left(\ln T^{*}\right)^{n}, T^{*}=\frac{\kappa T}{\varepsilon}, \frac{\varepsilon}{\kappa}=251.196
\end{gathered}
$$

where $T^{*}$ is the reduced temperature. The coefficients $l_{11}, l_{21}, l_{81}, l_{82}$, and $\lambda_{n}=0 \ldots 4$ can be found in Ref. [36].

\subsection{Boundary Conditions for Pressure and Temperature}

The pressure at all the edges of the pad and the pad's backside is equal to the ambient pressure $p_{a}$. The recess pressure $p_{r e}$ is constant throughout the recess region owing to the large recess depth relative to the film thickness in the land area [37]. The bearing and journal surface temperatures are set equal to the supply lubricant temperature [38]. The film flow temperature at the inlet of each pad is calculated using the thermal energy mixing model [28], which considers the mixture of the hot lubricant from the upstream pad with the cold (supplied) lubricant. 


\section{Numerical Procedure}

The current computational model and numerical scheme are based on those for hydrodynamic TPJBs considering pivot stiffness in Ref. [28], which is extended further to consider hydrostatic pressurization at the recess region, flow turbulence, and pressure/temperaturedependent thermochemical properties of the lubricant $\left(\mathrm{sCO}_{2}\right)$. The finite element method solves the Reynolds equation for pressure, the finite difference method solves the energy equation for the temperature distribution, and the Newton-Raphson method determines the equilibrium position. Figure 2 shows a flowchart of the numerical procedure.

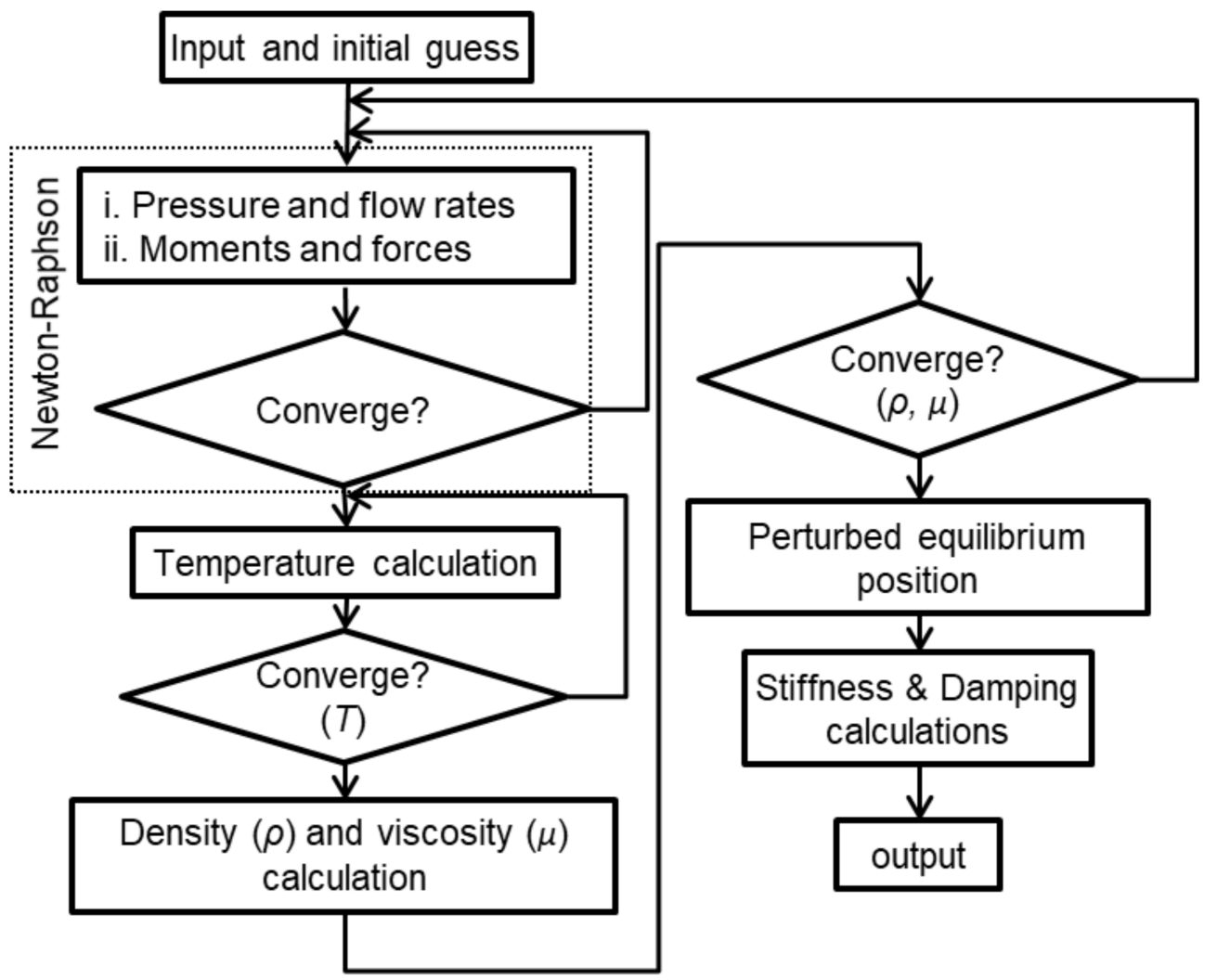

Figure 2. Flowchart of the numerical procedure.

Each step in Figure 2 is briefly explained as follows:

1. The bearing geometry, lubricant properties at the initial condition, the initial guesses for the pad tilting angle $\delta$, pivot deflection $\zeta$, eccentricity ratio $\epsilon$, the angle between the $X$-axis and the line of the centers $\theta_{c}$, and the pressure ratios $p_{\text {ratio }}\left(p_{\text {re }} / p_{s}\right), p_{\text {ratiod }}$ $\left(p_{d c} / p_{s}\right), p_{\text {ratioa }}\left(p_{d a} / p_{s}\right)$ are provided as the input. For the initial guess for $\delta$, Equation (4) assumes zero film thickness at the trailing edge of a pad, which indicates the maximum $\delta$. Half of the maximum $\delta$ is then taken as the initial guess for $\delta$ of each pad. The initial guess for $\zeta$ is $0.1 \%$ of the bearing clearance. Similarly, the initial guess for $\varepsilon, p_{\text {ratio }}, p_{\text {ratiod }}$, and $p_{\text {ratioa }}$ must be positive and less than 1 , and $\theta_{c}$ is guessed to be $90^{\circ}$, indicating that the rotor is displaced only in the vertical direction.

2. The finite element method solves the Reynolds equation to compute the pressure distribution over each pad. The generated hydrodynamic pressure exerts a force $F_{\text {pad }}$ on the surface of the pad, which deflects the supporting pivot and gives rise to a restoring force $F_{p}$ in it [28]. As shown in Equation (13), TPJB with the number of pads $N_{\text {pad }}$ in the static equilibrium requires that $F_{p}$ balance $F_{\text {pad }}$ all the moments and bearing horizontal force $F_{X}$ balance to zero, the bearing vertical force $F_{Y}$ balance the static load $F_{p 0}$, and the orifice flow rate $Q_{o}$ balance the summation of the flow rates at 
the recess boundaries $Q_{r}$. The circumferential and axial pressure drops at the recess edges due to inertia are also calculated iteratively as follows:

$$
\left\{\begin{array}{l}
{\left[F_{p a d}-F_{p}\right]_{n=1 \ldots N_{p a d}}} \\
M_{1 \ldots N_{p a d}} \\
\sum F_{X} \\
\sum F_{Y}-F_{p 0} \\
{\left[Q_{r}+Q_{o}\right]_{n=1 \ldots N_{p a d}}} \\
{\left[p_{d c_{i}}-p_{\left.d c_{i-1}\right]_{n=1 \ldots N_{p a d}}}\right.} \\
{\left[p_{d a_{i}}-p_{d a_{i-1}}\right]_{n=1 \ldots N_{p a d}}}
\end{array}\right\}=\left\{\begin{array}{l}
0 \\
0 \\
0 \\
0 \\
0 \\
0 \\
0
\end{array}\right\}
$$

where $i$ and $i-1$ denote the current and previous iterations, respectively. The Newton-Raphson method calculates the equilibrium position.

3. Once the static equilibrium position converges, the thermal energy mixing model calculates the fluid's inlet temperature at the pad's leading edge. The control-volume finite difference technique with an upwind scheme solves the two-dimensional energy equation (Equation (9)) for the temperature distribution (see Ref. [34] for more details).

4. The converged pressure and temperature are then used to calculate the density and viscosity.

5. Once the density and viscosity are converged iteratively using the successive substitution method, the journal is perturbed to a new position, and static equilibrium is achieved again.

6. The stiffness and damping coefficients are calculated from the ratio of the difference between the forces at the new and old equilibrium positions to the difference in distance and velocity, respectively, at both points. Note that the squeeze velocity term given on the right-hand side of the Reynolds equation accommodates the calculation of stiffness and damping coefficients.

\section{Model Validations}

The experimental and theoretical performance of hybrid TPJBs lubricated with $\mathrm{SCO}_{2}$ has not yet been reported. Therefore, we performed comprehensive model validations by comparing the obtained model predictions to the reported predictions or test data available in the literature for density and viscosity models of $\mathrm{SCO}_{2}$, load-carrying performance of $\mathrm{SCO}_{2}$-lubricated hydrodynamic journal bearings, and the load-carrying performance of a multi-recess hybrid journal bearing lubricated with low viscosity fluid, including water, operating with significant flow turbulence.

\subsection{Density and Viscosity of $\mathrm{sCO}_{2}$}

Figure 3 compares (a) density and (b) viscosity predictions plotted against pressure at a temperature of $37^{\circ} \mathrm{C}$ to the predictions from National Institute of Standards and Technology (NIST) [12]. Note that the predicted data from NIST are the most reliable for bearing lubrication models $[11,21]$. Both density and viscosity increase nonlinearly with an increase in pressure. The density and viscosity calculated using Equations (11) and (12), respectively, agree well with the predictions in Ref. [12].

\subsection{Fixed-Pad Hydrodynamic Journal Bearings}

Figure 4 compares the predicted static load versus eccentricity ratio for an $\mathrm{sCO}_{2}$ lubricated plain journal bearing to the predictions in Ref. [16] with incompressible and compressible fluid flows. The analyzed bearing has an axial length and a diameter of $40 \mathrm{~mm}(\mathrm{~L} / \mathrm{D}=1)$ with a radial clearance of $40 \mu \mathrm{m}$, and the rotating speed is $60 \mathrm{krpm}$ [16]. CFD model predictions using ANSYS FLUENT software are also compared with both predictions. In the CFD model, the ANSYS design modeler is used to create the fluid film 
model. The fluid film is meshed with 10 divisions in the radial direction and 900 divisions in the circumferential direction, and it has an element face size of $0.4 \mathrm{~mm}$ in the axial direction, resulting in 900,000 hexahedron elements. The interfaces attached to the bearing and journal sides are specified as stationary and rotating no-slip walls, respectively. Threedimensional (3D) compressible Reynolds-averaged Navier-Stokes (RANS) with an SST k-omega turbulence model is solved using a coupled numerical scheme until the predefined convergence criteria are reached. Note that the CFD tool also uses Equations (11) and (12) to model the density and viscosity of $\mathrm{sCO}_{2}$, respectively. The static load increases nonlinearly with the eccentricity ratio for all predictions. Compressible fluid flow models show higher load capacity than the incompressible ones, particularly for high eccentricity ratios, because the density and viscosity of compressible fluids $\left(\mathrm{sCO}_{2}\right)$ increase with an increase in hydrodynamic pressure under heavy loads (Figure 3). The current bulk flow model predictions agree well with those obtained using CFD. For the compressible fluid flow model, the discrepancies between the current model predictions and those reported in Ref. [16] can be attributed to the difference in the density and viscosity models. Reference [16] treats $\mathrm{sCO}_{2}$ as an isoviscous ideal gas, whereas the proposed model considers it a real gas with temperature- and density-dependent viscosity. The mean square errors for the current predictions and those in Ref. [16] are $0.13 \%$ and $0.35 \%$ for incompressible and compressible fluids, respectively.
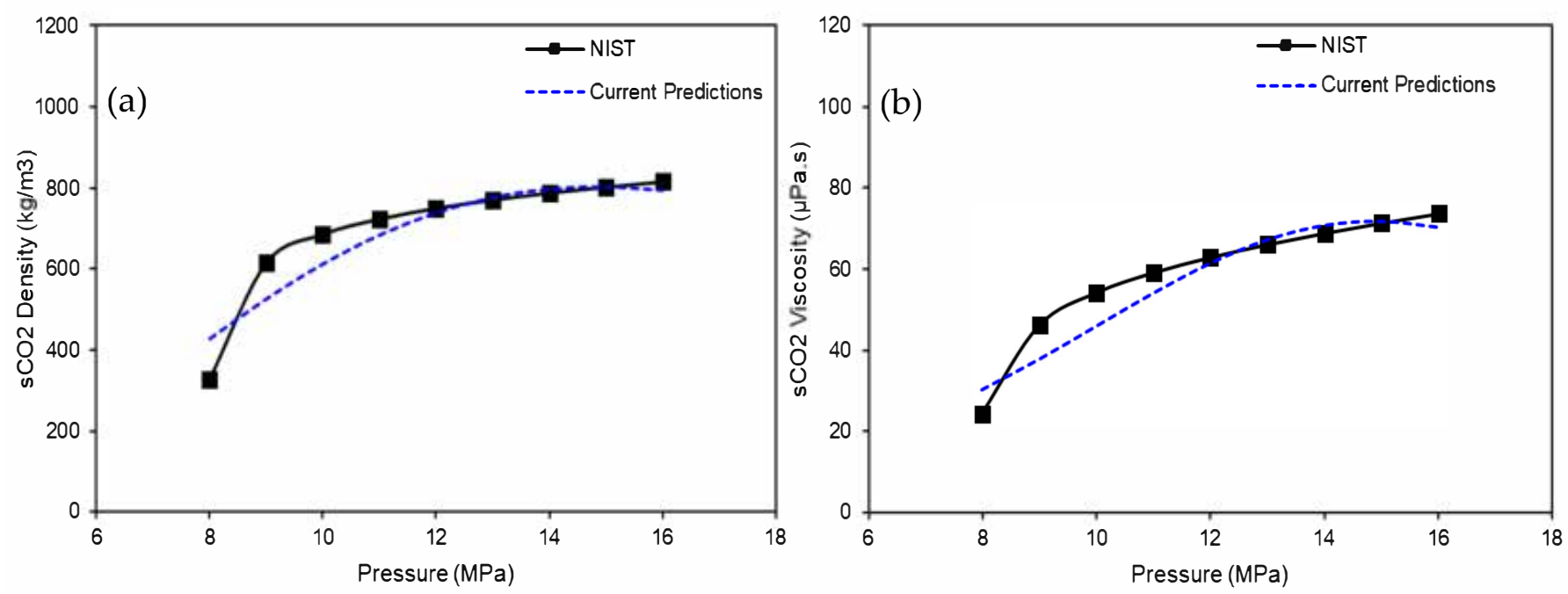

Figure 3. (a) Density and (b) viscosity of supercritical carbon dioxide $\left(\mathrm{sCO}_{2}\right)$ vs. pressure at $37^{\circ} \mathrm{C}$. Comparison between the developed model and that in NIST [12].

\subsection{Fixed-Pad Hydrostatic and Hybrid Journal Bearings}

The test data for the water-lubricated, three-recess hybrid fixed-pad journal bearing reported in Ref. [39] validate the proposed bulk flow model for hydrostatic/hydrodynamic hybrid operations. The analyzed bearing has an axial length and a diameter of $80 \mathrm{~mm}$ $(\mathrm{L} / \mathrm{D}=1)$ with a radial clearance of $125 \mu \mathrm{m}$. The circumferential angle and width of the recess are $90^{\circ}$ and $50 \mathrm{~mm}$, respectively, and the recess depth is $10 \mathrm{~mm}$ [39]. The low viscosity of water may lead to flow turbulence at high operating speeds and significant fluid inertia at recess edges. Figure 5 compares the predicted static load plotted against the eccentricity ratio with the test data from Ref. [39] at $0 \mathrm{rpm}$, i.e., pure hydrostatic operation. In general, the predictions agree well with the test data, with a mean square error of $0.3 \%$. 


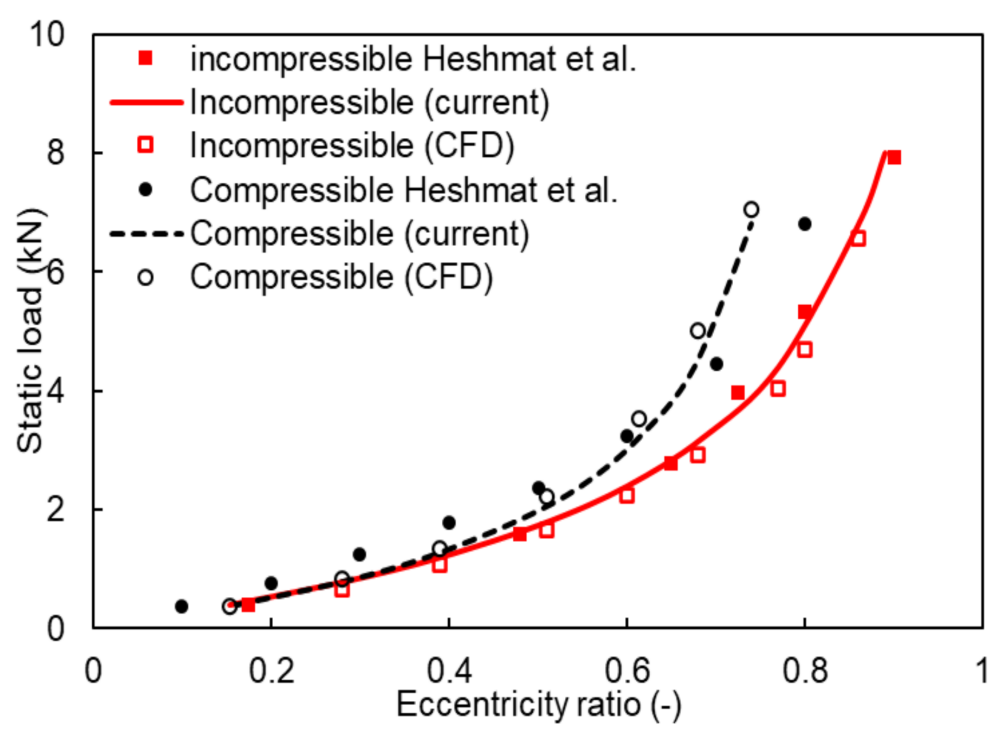

Figure 4. Static load vs. eccentricity ratio for compressible and incompressible fluid flows compared to the predictions in Ref. [16] and those obtained using computational fluid dynamics (CFD). Rotor speed $=60 \mathrm{krpm}$.

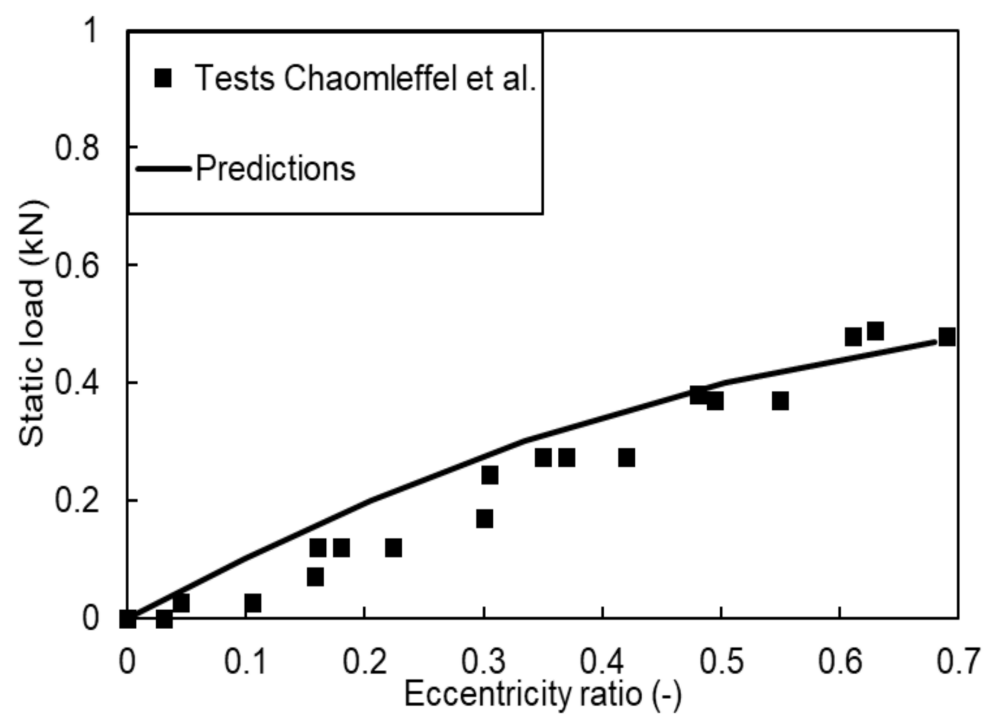

Figure 5. Static load vs. eccentricity ratio for a fixed-pad three-recess hybrid journal bearing compared to test data in Ref. [39]. $P_{S}=0.4 \mathrm{MPa}$, and rotor speed $=0 \mathrm{rpm}$ (hydrostatic operation).

Figure 6 shows the predicted centerline pressure ratio $\left(P / P_{s}\right)$ compared to the test data from Ref. [39] at rotor speeds of 5 and $8 \mathrm{krpm}$ with a static load of $356 \mathrm{~N}$ applied at $270^{\circ}$. Note that the figure shows one-third of the bearing geometry and film pressure between two externally pressurized flow supply tubes located circumferentially at $210^{\circ}$ and $330^{\circ}$. The predicted pressure ratios are compared to test data measured at 11 locations from $210^{\circ}$ to $310^{\circ}$ with an increment of $10^{\circ}$. The film pressure ratio is higher at the recess regions. The sudden pressure drop at the entrance of the film land is attributed to the increase in the flow inertia with an increase in rotor speed. The predictions agree well with test data with mean square errors of $0.04 \%$ and $0.05 \%$ for 5 - and 8 -krpm rotor speeds, respectively, thus validating the proposed bearing model for hybrid operations. 


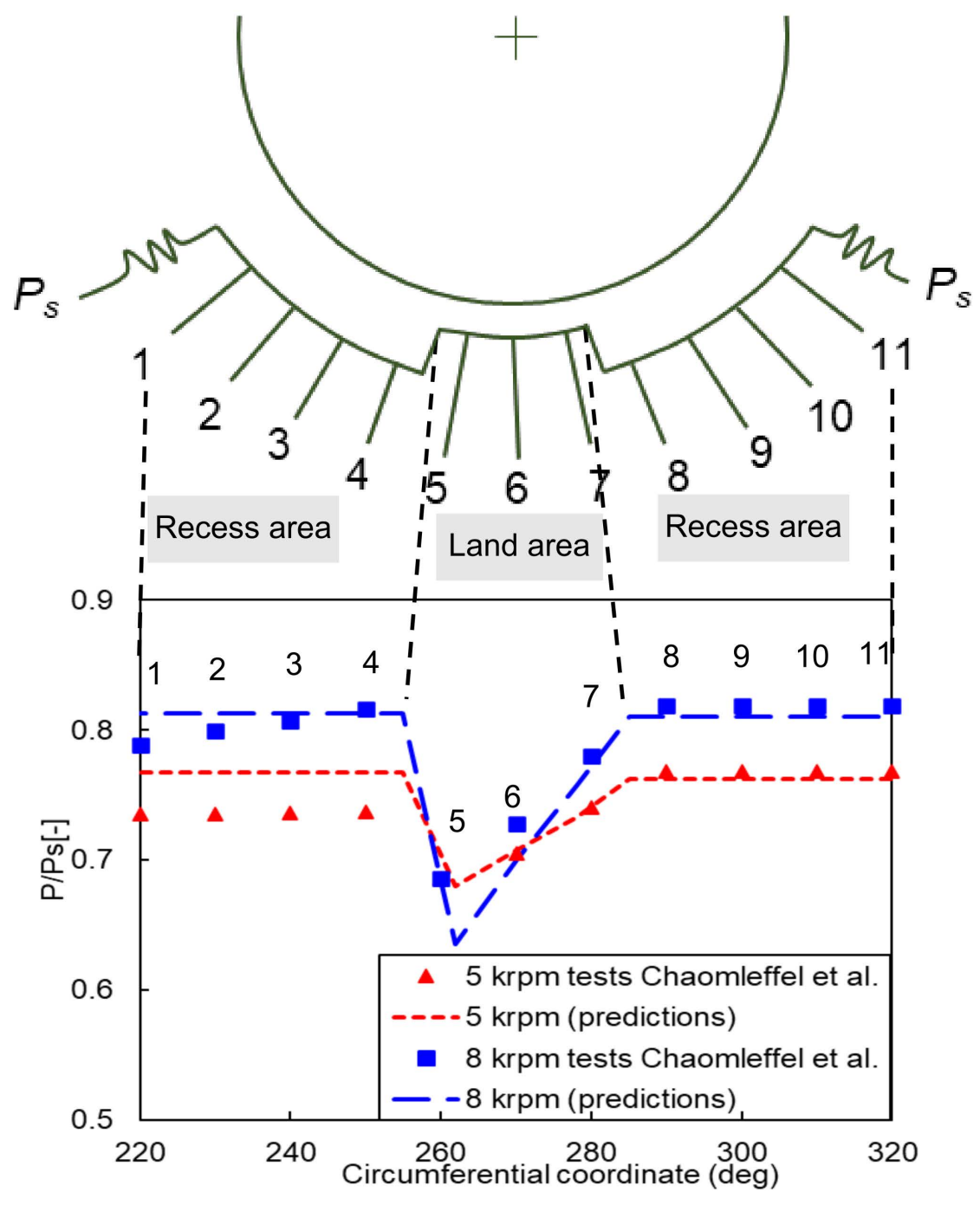

Figure 6. Centerline pressure vs. circumferential coordinates (from $220^{\circ}$ to $320^{\circ}$ ) for a fixed-pad three-recess hybrid journal bearing compared to the test data reported in Ref. [39]. $P_{S}=0.4 \mathrm{MPa}$, and static load $=356 \mathrm{~N}$. Rotor speed $=5$ and $8 \mathrm{krpm}$ (hybrid operation).

\section{Results}

Table 1 lists TPJB, pivot, and recess geometries and the properties of $\mathrm{sCO}_{2}$ at the initial condition. The journal diameter and axial pad length are both equal to $25 \mathrm{~mm}$. The four pads, each with an angular extent of $70^{\circ}$, a pad thickness of $8 \mathrm{~mm}$, a pivot offset of 0.5 , and a preload factor of 0.5 , constitute the TPJB. The pivot is of the rocker-back shape, a cylindrical type whose radius is $18 \mathrm{~mm}$ with a housing radius of $21 \mathrm{~mm}$. The rocker-back pivot length is equal to the bearing length $(25 \mathrm{~mm})$. Each pad has a rectangular recess whose geometrical center is concentric with the pad's pivot. The recess has a circumferential length of $5 \mathrm{~mm}\left(22.9^{\circ}\right)$, an axial length of $5 \mathrm{~mm}$, and a depth of $0.1 \mathrm{~mm}$, thus covering about $6.67 \%$ of the pad area. The orifice at the center of the recess has a diameter of $0.5 \mathrm{~mm}$, and the orifice discharge coefficient is 0.68 [31]. The bearing is lubricated with $\mathrm{sCO}_{2}$ with an ambient pressure and temperature of $8.0 \mathrm{MPa}$ and $37^{\circ} \mathrm{C}$, respectively, at which its density and viscosity are $426.6 \mathrm{~kg} / \mathrm{m}^{3}$ and $30.4 \mu \mathrm{Pa} \cdot \mathrm{s}$, respectively. The temperature of the high-pressure $\mathrm{sCO}_{2}$ supplied through the orifice is similar to that of the ambiance. Note that $\mathrm{sCO}_{2}$ supplied through the orifice must have a higher pressure than the ambient pressure to pressurize the bearing hydrostatically. 
Table 1. Tilting-pad journal bearing (TPJB), pivot, and recess geometries and lubricant properties.

\begin{tabular}{|c|c|c|}
\hline & Parameters & Values \\
\hline \multirow{9}{*}{ ТРЈB } & Load configuration & LBP \\
\hline & Journal diameter, $D(\mathrm{~mm})$ & 25 \\
\hline & Pad axial length, $L$ (mm) & 25 \\
\hline & Number of pads, $N_{\text {pad }}(-)$ & 4 \\
\hline & Pad arc angle, $\theta_{\text {pad }}(\mathrm{deg})$ & 70 \\
\hline & Pad thickness, $t_{p}(\mathrm{~mm})$ & 8.0 \\
\hline & Pivot offset (-) & 0.5 \\
\hline & Radial pad clearance, $C_{p}(\mu \mathrm{m})$ & 67 \\
\hline & Preload factor, $m(-)$ & 0.5 \\
\hline \multirow{5}{*}{ Pivot } & Pivot type & Rocker-back \\
\hline & Pivot's housing radius, $R_{h}(\mathrm{~mm})$ & 21.0 \\
\hline & Pivot radius, $R_{p}(\mathrm{~mm})$ & 18.0 \\
\hline & Rocker-back length, $L_{R}(\mathrm{~mm})$ & 25.0 \\
\hline & Young's modulus, E (GPa) & 200 \\
\hline \multirow{6}{*}{ Recess } & Recess type & Rectangular \\
\hline & Circumferential length of recess, $l(\mathrm{~mm})$ & 5.0 \\
\hline & Axial length of recess, $b(\mathrm{~mm})$ & 5.0 \\
\hline & Depth of recess, $D_{r}(\mathrm{~mm})$ & 0.1 \\
\hline & Orifice diameter, $d_{o}(\mathrm{~mm})$ & 0.5 \\
\hline & Orifice discharge coefficient, $C_{d}$ & 0.68 \\
\hline \multirow{5}{*}{ Lubricant } & Lubricant type & $\mathrm{sCO}_{2}$ \\
\hline & Pressure, $P_{a}(\mathrm{MPa})$ & 8.0 \\
\hline & Temperature, $T_{a}\left({ }^{\circ} \mathrm{C}\right)$ & 37 \\
\hline & Density, $\rho_{0}\left(\mathrm{~kg} / \mathrm{m}^{3}\right)$ & 426.6 \\
\hline & Viscosity, $\mu_{0}(\mu \mathrm{Pa} \cdot \mathrm{s})$ & 30.4 \\
\hline
\end{tabular}

Figure 7 shows plots of the 3D distributions of the (a) pressure, (b) temperature, (c) density, and (d) viscosity of the lubricant $\left(\mathrm{sCO}_{2}\right)$ over each pad for hybrid TPJB with pressurized recesses. The supply pressure of $\mathrm{sCO}_{2}$ at the orifice is $10 \mathrm{MPa}$, and the static load applied at $270^{\circ}$ and rotor speed are $100 \mathrm{~N}$ and $60 \mathrm{krpm}$, respectively. Each pad has peak constant pressure at the recess region. The loaded pads (pads 3 and 4 ) have the highest recess pressure, whereas the unloaded pads (pads 1 and 2) have the lowest values. The temperature is lowest at the pad leading edge and highest at the trailing edge. For each pad, the stepped track from the recess toward the trailing edge is attributed to the cooling effect of the fresh orifice flow. The density and viscosity of $\mathrm{sCO}_{2}$ are maximum at the recess region. The loaded pads (pads 3 and 4) have the highest values, whereas the unloaded pads (pads 1 and 2) have the lowest values, similar to the case of pressure. Though the density and viscosity of $\mathrm{sCO}_{2}$ are functions of both pressure and temperature, it mainly follows the trend of the film pressure, as the temperature rise is relatively insignificant owing to the large specific heat of the lubricant.

Figure 8 shows the 3D distributions of (a) pressure, (b) temperature, (c) density, and (d) viscosity of $\mathrm{sCO}_{2}$ over pads for conventional hydrodynamic TPJB without recesses but with a load and speed similar to those in Figure 7. The loaded pads (pads 3 and 4) have the highest hydrodynamic pressure, whereas the unloaded pads (pads 1 and 2) have the lowest pressure. Note the relatively small film pressure on the unloaded pads for the hydrodynamic TPJB compared to that of hybrid TPJB. The film temperature rises from the lowest value at the leading edge of the unloaded pad (pad 1) to the maximum value at the trailing edge of the loaded pad (pad 4). Note that hydrodynamic TPJB has a higher temperature than hybrid TPJB, particularly at the loaded pads; the hydrostatically pressurized fresh fluid flow from the orifice cools the film for hybrid TPJB. Temperature changes in the axial direction are relatively insignificant, as in hybrid TPJBs. 

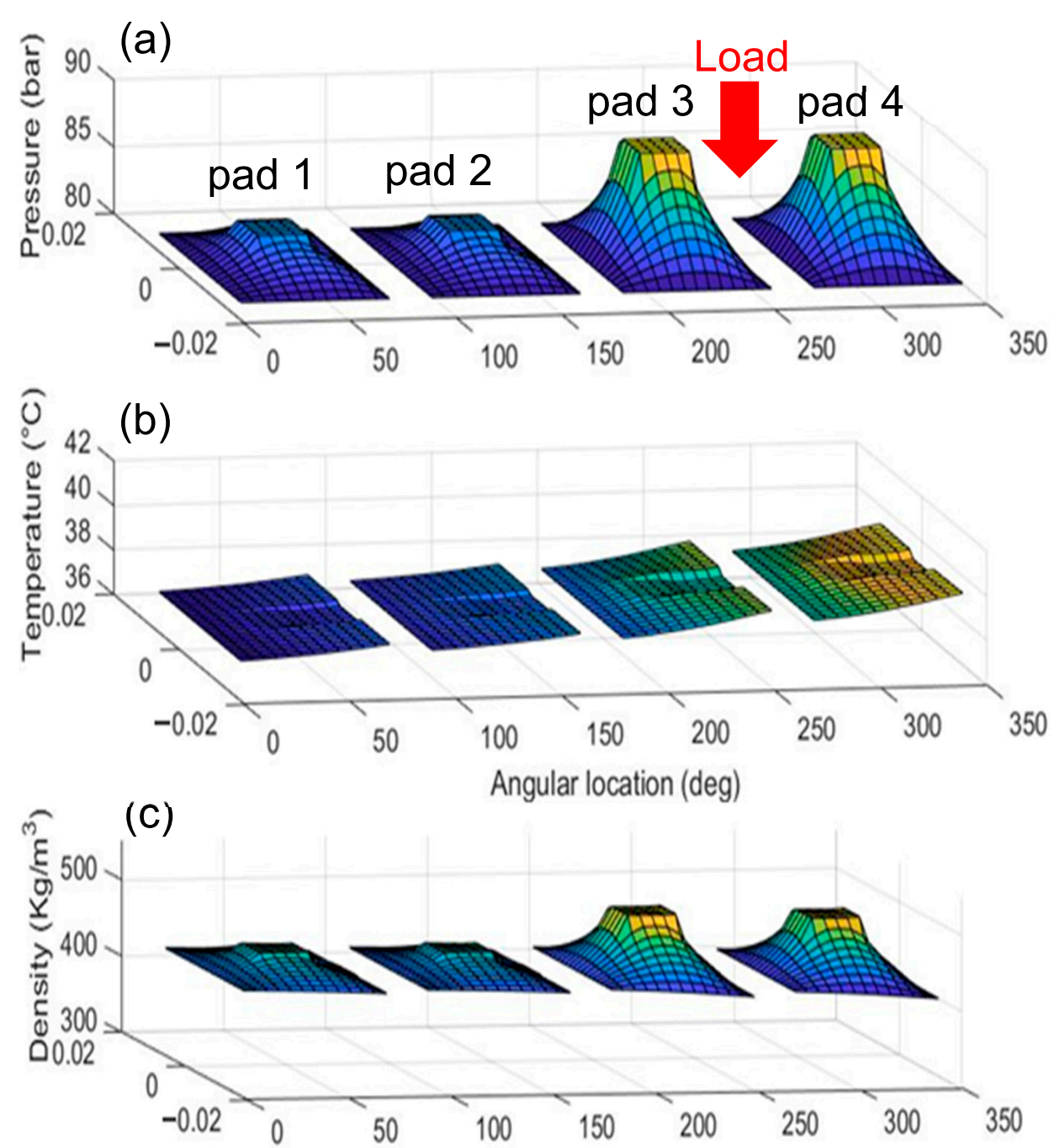

(d)

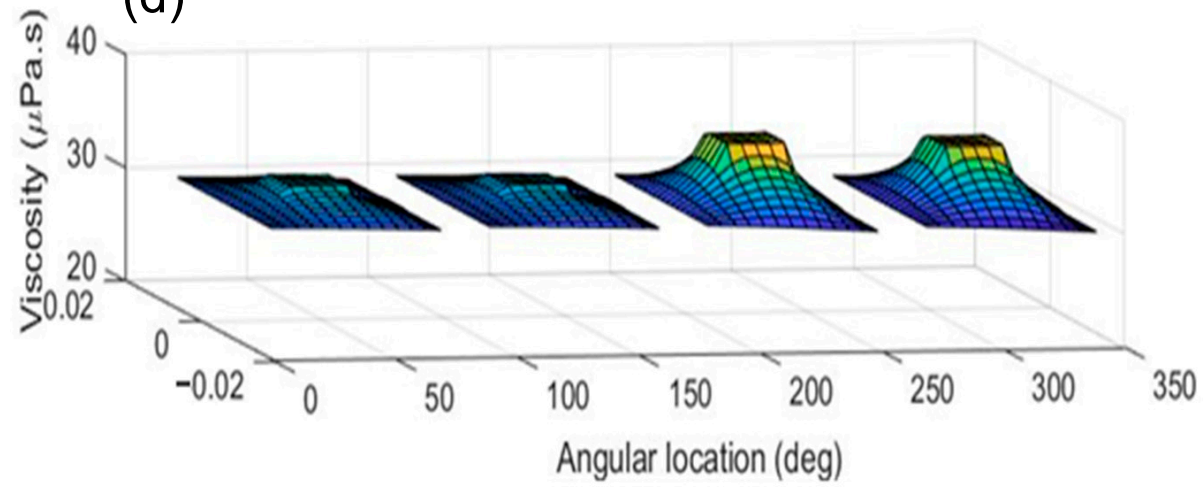

\section{Hybrid operation with pressurized recesses}

Figure 7. Three-dimensional plots of (a) pressure, (b) temperature, (c) density, and (d) viscosity for hybrid tilting-pad journal bearing with $p_{S}=10 \mathrm{MPa}$ for each pad. Static load $=100 \mathrm{~N}$, and rotor speed $=60 \mathrm{krpm}$. 


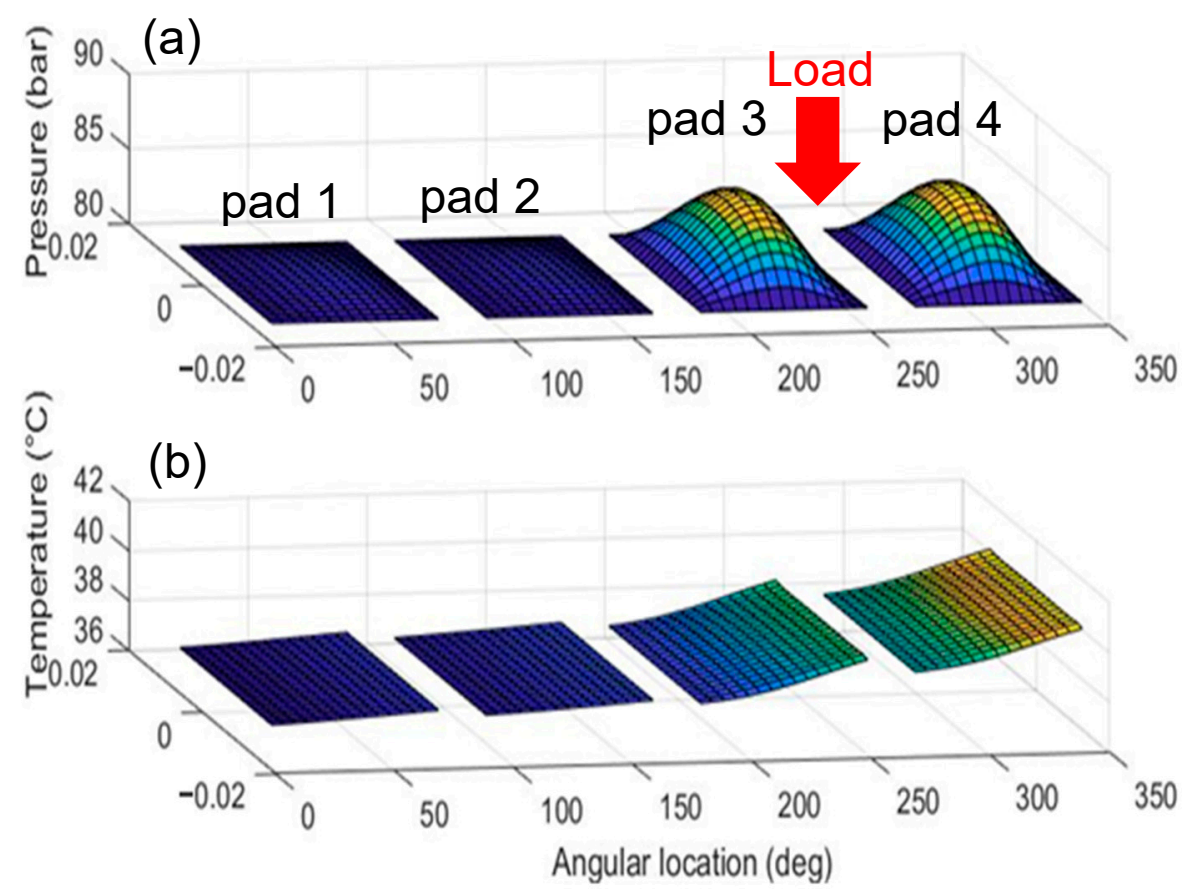

(c)

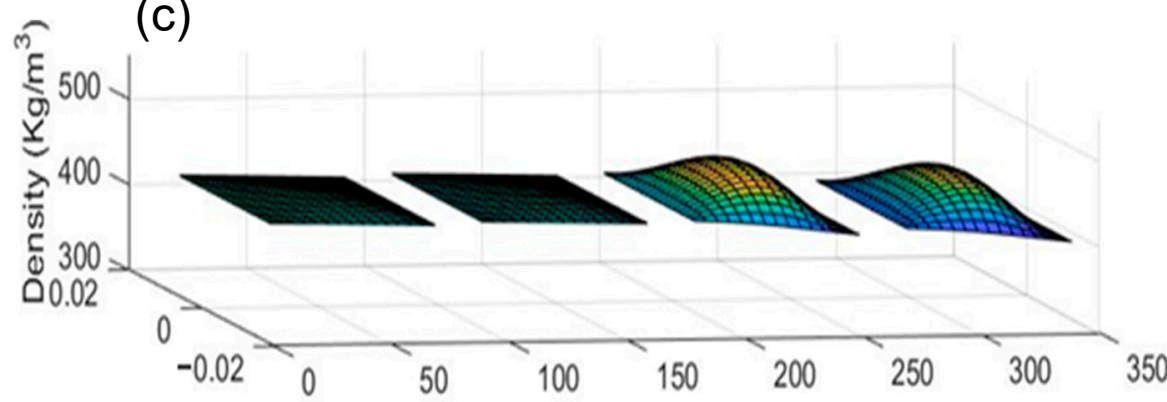

(d)

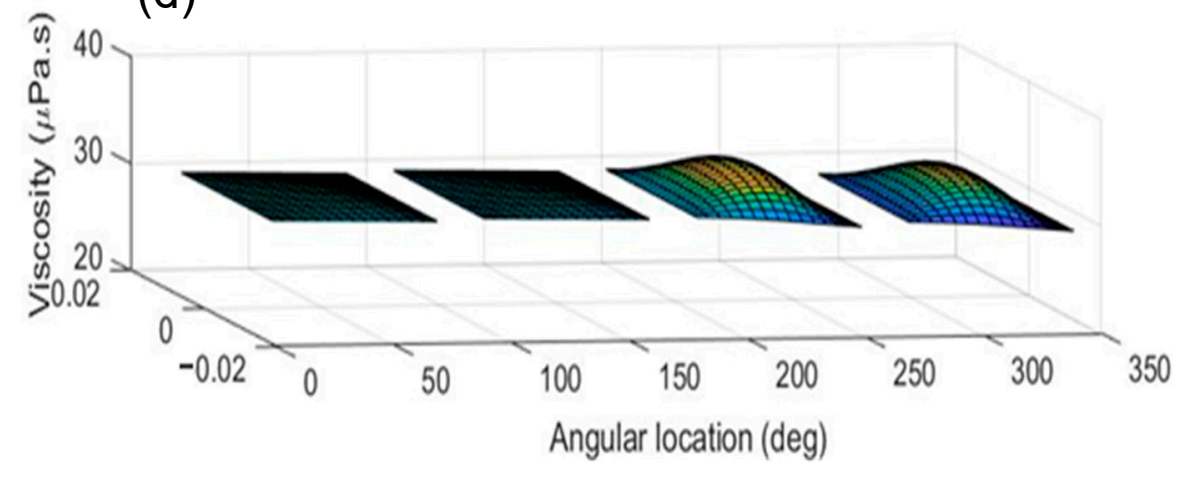

\section{Hydrodynamic operation without recesses}

Figure 8. Three-dimensional plots of (a) pressure, (b) temperature, (c) density, and (d) viscosity for hydrodynamic tilting-pad journal bearings without recesses. Static load $=100 \mathrm{~N}$, and rotor speed $=60 \mathrm{krpm}$.

Figure 9 shows the centerline (a) film thickness, (b) pressure, and (c) temperature plotted against the circumferential coordinate for the supply pressures of 10,15, and $20 \mathrm{MPa}$ for the hybrid TPJB with a static load of $100 \mathrm{~N}$ and rotor speed of $60 \mathrm{krpm}$. The predictions for the hydrodynamic TPJB without recesses are also presented for comparison purposes. Note that the large film thickness at the recess area for hybrid TPJBs is due to 
the recess depth of $0.1 \mathrm{~mm}$. The film thickness for hybrid TPJBs is larger than that for the hydrodynamic TPJB at the loaded pads, and it increases with an increase in supply pressure. The centerline pressure for the hybrid TPJB is also greater than that of the hydrodynamic TPJB and increases with an increase in the supply pressure for both loaded and unloaded pads. The pressure drop is attributed to the inertia effects at the boundary edges of the recess, as experimentally obtained in Ref. [39]. The pad tilting angle, pivot radial deflection, and maximum pivot stress for different supply pressures are provided in Appendix A. The pad tilting angle generally decreases, and the pivot deflection and maximum stress increase with an increase in the supply pressure. The predicted values for the pivots are not fatal when considering the pad's and pivot's mechanical and material design limits. The predicted centerline temperature for the hybrid TPJB at the unloaded pads is slightly higher than that of the hydrodynamic TPJB. At the loaded pads, hybrid TPJB has a higher temperature than the hydrodynamic TPJB until the trailing edge of the recess of pad 3 , after which it becomes lower owing to the influence of externally pressurized $\mathrm{sCO}_{2}$. The result shows that the freshly supplied $\mathrm{sCO}_{2}$ cools the hybrid TPJB effectively, particularly in the loaded region.

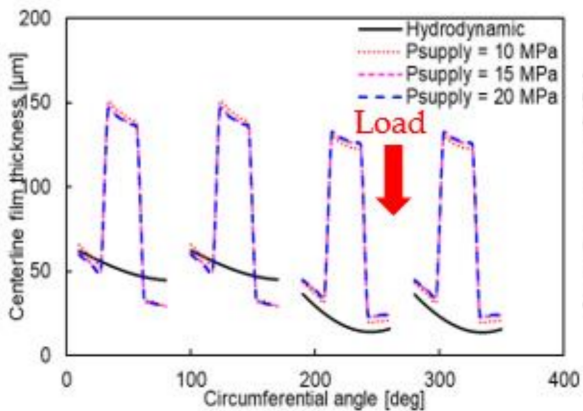

(a)

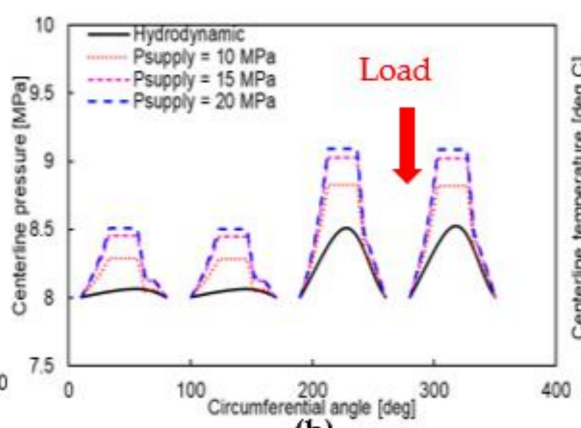

(b)

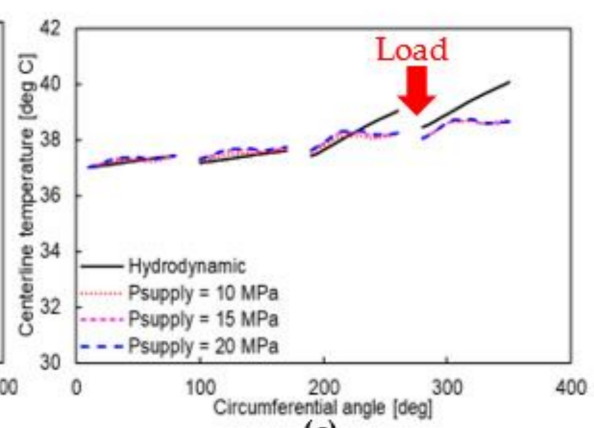

(c)

Figure 9. Centerline (a) film thickness, (b) pressure, and (c) temperature vs. circumferential coordinate for increasing supply pressures. Static load $=100 \mathrm{~N}$, and rotor speed $=60 \mathrm{krpm}$.

Figure 10 shows the centerline (a) density and (b) viscosity of an $\mathrm{sCO}_{2}$ film flow versus the circumferential coordinate for different supply pressures. As expected, the density increases significantly with an increase in supply pressure following the trends of the centerline pressure in Figure 9b. Note that the density at the loaded pads' trailing edges becomes smaller than the ambient value $\left(426 \mathrm{~kg} / \mathrm{m}^{3}\right)$ because of the significant temperature rise in Figure 9c. The viscosity follows the trends of the density with an increase in supply pressure.

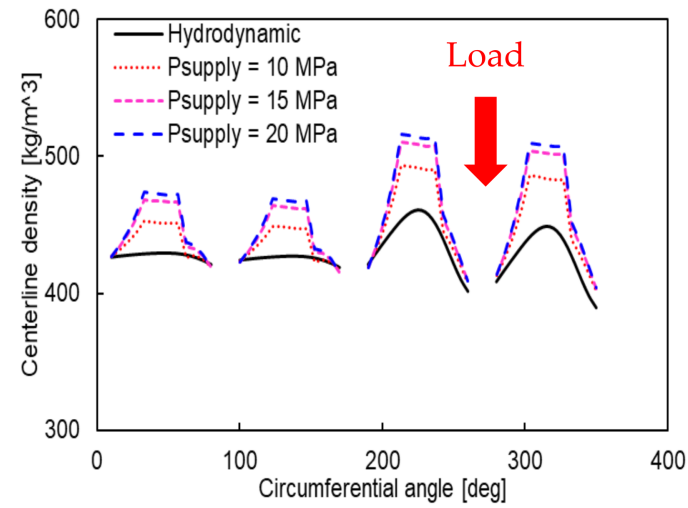

(a)

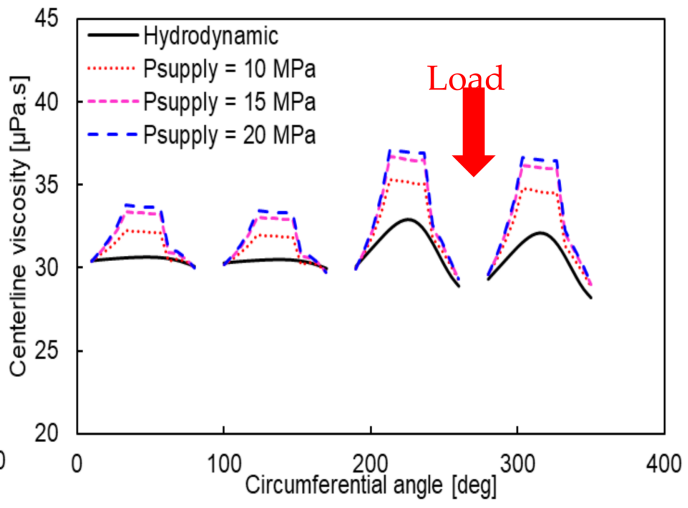

(b)

Figure 10. Centerline (a) density and (b) viscosity vs. circumferential coordinate for increasing supply pressures. Static load $=100 \mathrm{~N}$, and rotor speed $=60 \mathrm{krpm}$. 
Figure 11 shows the journal eccentricity ratio versus rotor speed for different supply pressures at a static load of $100 \mathrm{~N}$. An increase in the supply pressure dramatically reduces the eccentricity ratio. The decrease in journal eccentricity with a supply pressure of $20 \mathrm{MPa}$ is $\sim 65 \%$ compared to that for hydrodynamic TPJB at $60 \mathrm{krpm}$. The journal eccentricity ratio also decreases as the rotor speed increases owing to the increased hydrodynamic effect. However, the effect of the rotor speed on the eccentricity is relatively less significant for hybrid TPJBs, as in Refs. [23,24].

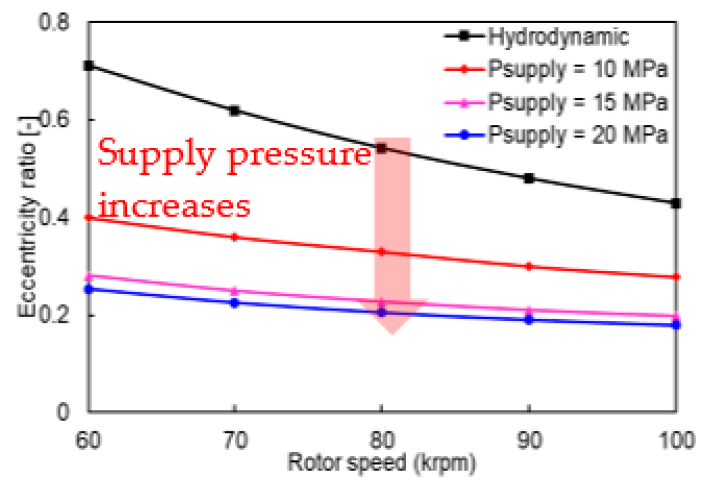

Figure 11. Journal eccentricity ratio vs. rotor speed for increasing supply pressures. Static load $=100 \mathrm{~N}$.

Figure 12 displays the minimum film thickness versus rotor speed for increasing supply pressures. In general, the minimum film thickness is greater for the hybrid TPJB than for hydrodynamic TPJB owing to the decreased eccentricity ratio, and it further increases with an increase in the supply pressure. The minimum film thickness for the hybrid TPJB with a supply pressure of $20 \mathrm{MPa}$ increases by $\sim 80 \%$ compared with that for the hydrodynamic case at the lowest rotor speed. The minimum film thickness increases with increasing rotor speed; however, the degree of increment for the hybrid TPJB is lower than that for the hydrodynamic TPJB. The significant increment in the minimum film thickness indicates a considerable improvement in the load capacity due to the external pressurization.

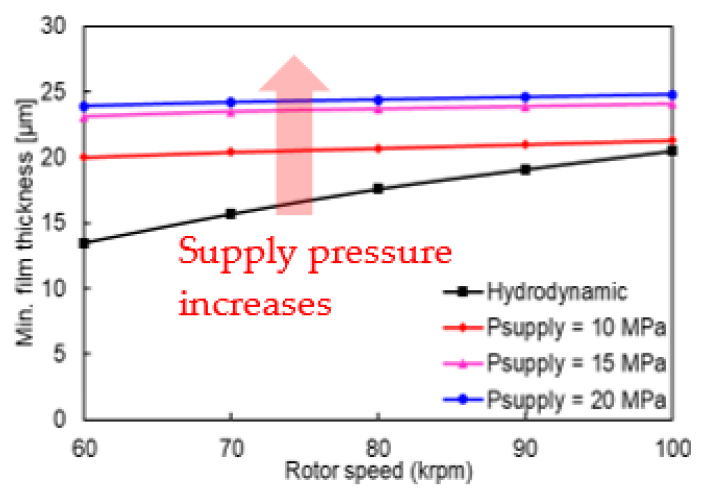

Figure 12. Minimum film thickness vs. rotor speed for increasing supply pressures. Static load $=100 \mathrm{~N}$.

Figure 13 shows the variation of the maximum film pressure with increasing rotor speed for different supply pressures. The maximum pressure increases with an increase in the supply pressure and rotor speed. The hydrodynamic TPJB has the lowest maximum pressure. As shown in Figure 14, the predicted bearing drag power loss increases nonlinearly with the rotor speed. The hybrid TPJB has a higher power loss than the hydrodynamic TPJB because of the increase in the viscosity of $\mathrm{sCO}_{2}$. The change in power loss as the supply pressure increases from 10 to $20 \mathrm{MPa}$ is small. 


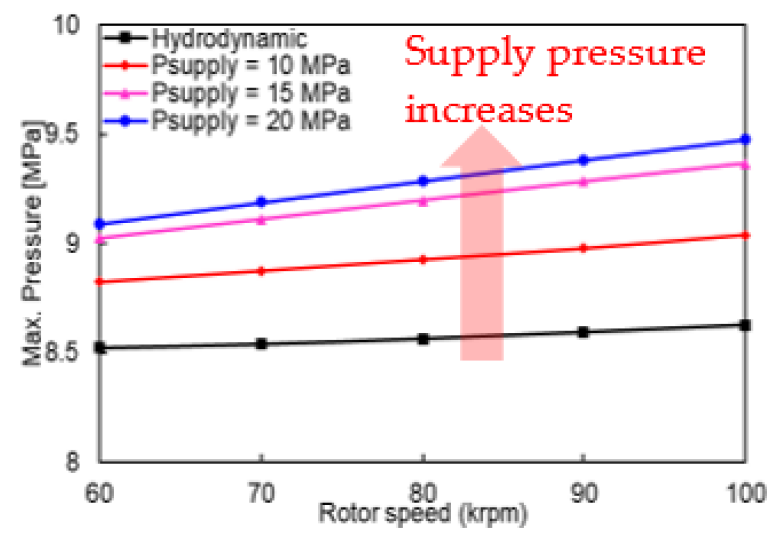

Figure 13. Maximum pressure vs. rotor speed for increasing supply pressures. Static load = $100 \mathrm{~N}$.

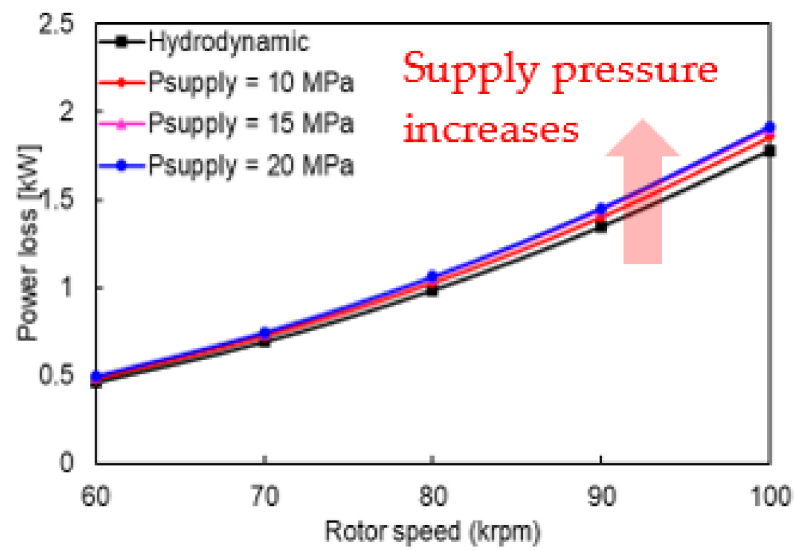

Figure 14. Power loss vs. rotor speed for increasing supply pressures. Static load $=100 \mathrm{~N}$.

Figure 15 shows the direct stiffness coefficient plotted against the rotor speed for the increasing supply pressures. The stiffness coefficient increases with an increase in rotor speed for both hydrodynamic and hybrid lubrication. Most importantly, external pressurization significantly increases the stiffness coefficient. Note that the stiffness increases by $\sim 85 \%$ for a supply pressure of $20 \mathrm{MPa}$ compared to that for the hydrodynamic TPJB at the highest rotor speed. As shown in Figure 16, the direct damping coefficient decreases slightly with an increase in rotor speed. The increasing supply pressure increases the damping coefficient, as in Ref. [20]. The hybrid TPJB predicts damping coefficients lower than those of the hydrodynamic TPJB without recesses.

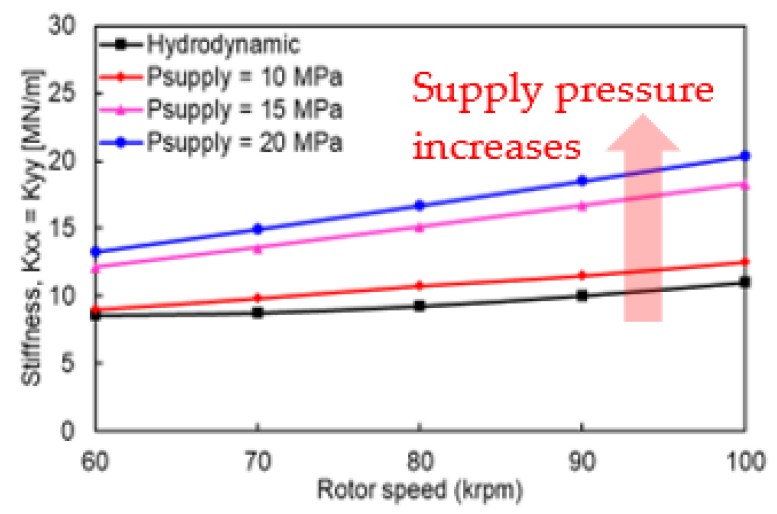

Figure 15. Stiffness coefficient vs. rotor speed for increasing supply pressures. Static load $=100 \mathrm{~N}$. 


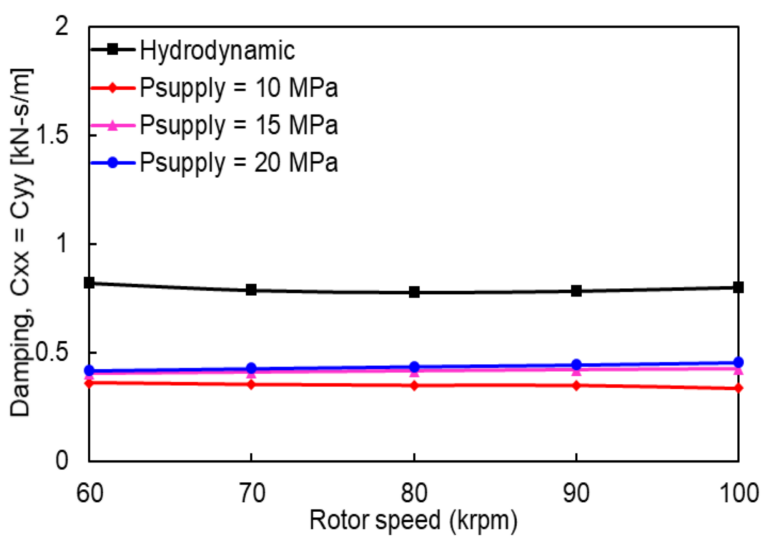

Figure 16. Damping coefficient vs. rotor speed for increasing supply pressures. Static load = $100 \mathrm{~N}$.

\section{Conclusions}

$\mathrm{sCO}_{2}$-lubricated TPJBs enable a simple configuration of turbomachinery for $\mathrm{sCO}_{2}$ power cycles by eliminating not only the issue of mixing-up of oil lubricant and $\mathrm{sCO}_{2}$ process fluid but also the need for oil pumps and sealing devices for the lubricant.

The present study develops a computational model for $\mathrm{sCO}_{2}$-lubricated TPJB with hydrostatic pressurization at the tilting pad recesses to improve its static and dynamic performances. The finite element and finite difference methods solve the Reynolds and energy equations for the pressure and temperature distributions, respectively. The NewtonRaphson method is employed to find the equilibrium position, and the successive substitution method finds the numerical solution for the local density and viscosity of $\mathrm{sCO}_{2}$, which depend nonlinearly on pressure and temperature.

The models for the density and viscosity of $\mathrm{sCO}_{2}$, hydrodynamic lubrication with compressible and incompressible fluid flows, and hydrostatic lubrication with a turbulent flow and high Reynolds numbers are validated by comparing their results with predictions and test data in the literature. A parametric study of the hybrid TPJB reveals that an increase in supply pressure significantly increases the pad pressure. At a rotor speed of $60 \mathrm{krpm}$, with an increase in supply pressure, the journal eccentricity decreases by $65 \%$, and the minimum film thickness increases by $80 \%$, thus enhancing the load capacity compared to that of the hydrodynamic TPJB. Hydrostatic pressurization has the most significant effects on the load capacity at the lowest rotor speed, where hydrodynamic pressure generation is the lowest. The stiffness coefficients increase, but the damping coefficients decrease owing to external pressurization. For the hybrid TPJB, with an increase in the supply pressure, the stiffness significantly increases, but the damping coefficients change slightly.

Author Contributions: Conceptualization, S.M.M. and T.H.K.; methodology, S.M.M.; model development, S.M.M.; formal analysis, S.M.M.; writing—original draft preparation, S.M.M.; writing—review and editing, T.H.K.; supervision, T.H.K.; project administration, T.H.K.; funding acquisition, T.H.K. All authors have read and agreed to the published version of the manuscript.

Funding: This study was supported by the National Research Foundation of Korea (NRF) grant funded by the Korea Ministry of Science and ICT (MSIT) (No. NRF2021R1F1A105960211), "Feasibility Study on High-Speed, Long-Life Bearing-Seal Units in Turbopumps for Small Reusable Liquid-Propellant Space Launch Vehicles" and the Korea Energy Technology Evaluation and Planning (KETEP) grant funded by the Korea Ministry of Trade, Industry and Energy (MOTIE) (No. 2021202080026D), “Development of Infrastructure/Platform Technology and Operation Management System for AI/ICT-Based Variable Fluid Device Design and Condition Diagnosis."

Institutional Review Board Statement: Not applicable.

Informed Consent Statement: Not applicable.

Data Availability Statement: Not applicable. 
Acknowledgments: This work was supported by the National Research Foundation of Korea (NRF) grant funded by the Korea Ministry of Science and ICT (MSIT) (Grant No. NRF2021R1F1A105960211) and the Korea Energy Technology Evaluation and Planning (KETEP) grant funded by the Korea Ministry of Trade, Industry and Energy (MOTIE) (Grant No. 2021202080026D). The first author acknowledges the support of the Global Scholarship Program for Foreign Graduate Students at Kookmin University, South Korea.

Conflicts of Interest: The authors declare that they have no conflicts of interest.

\section{Nomenclature}

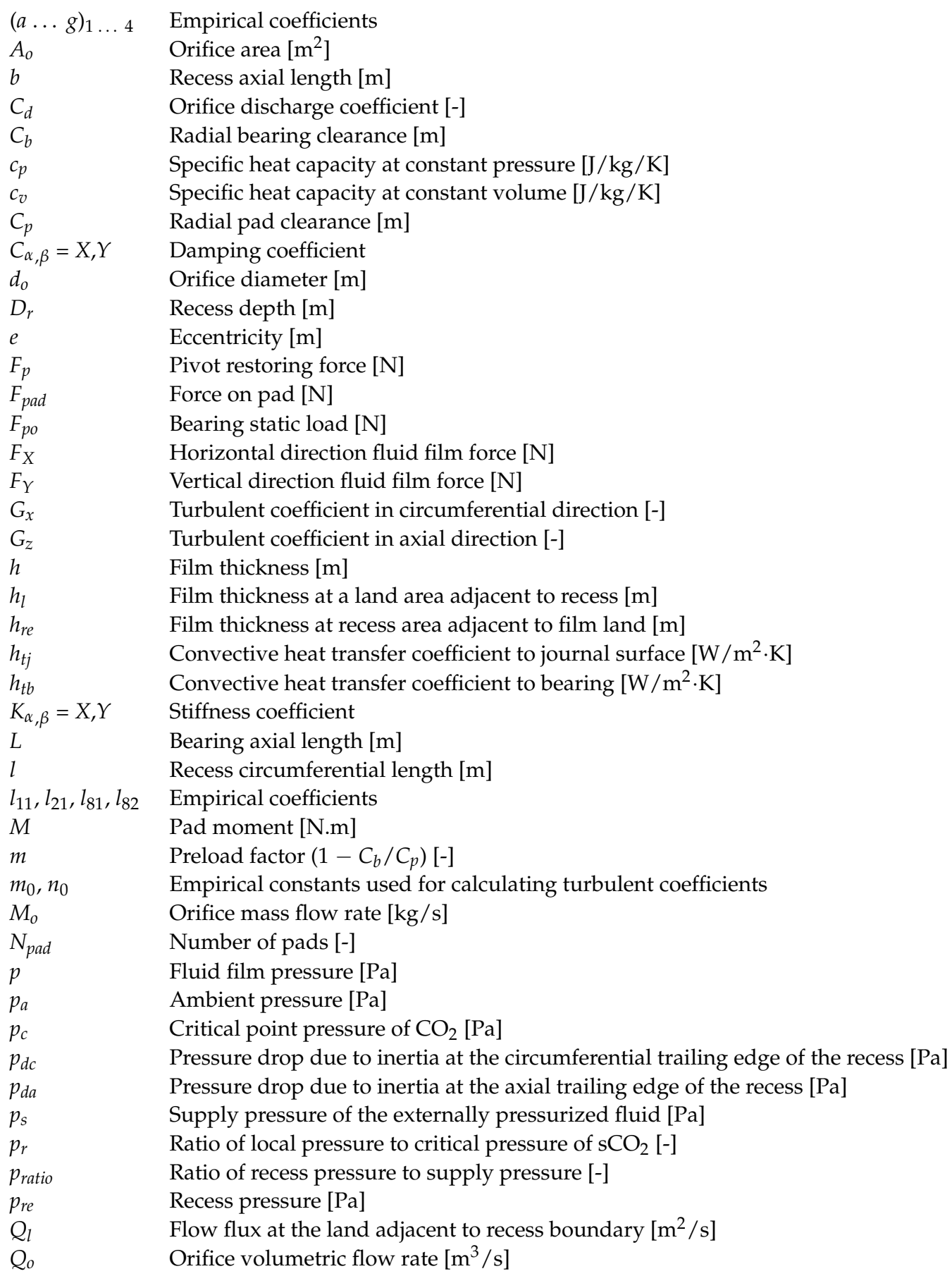




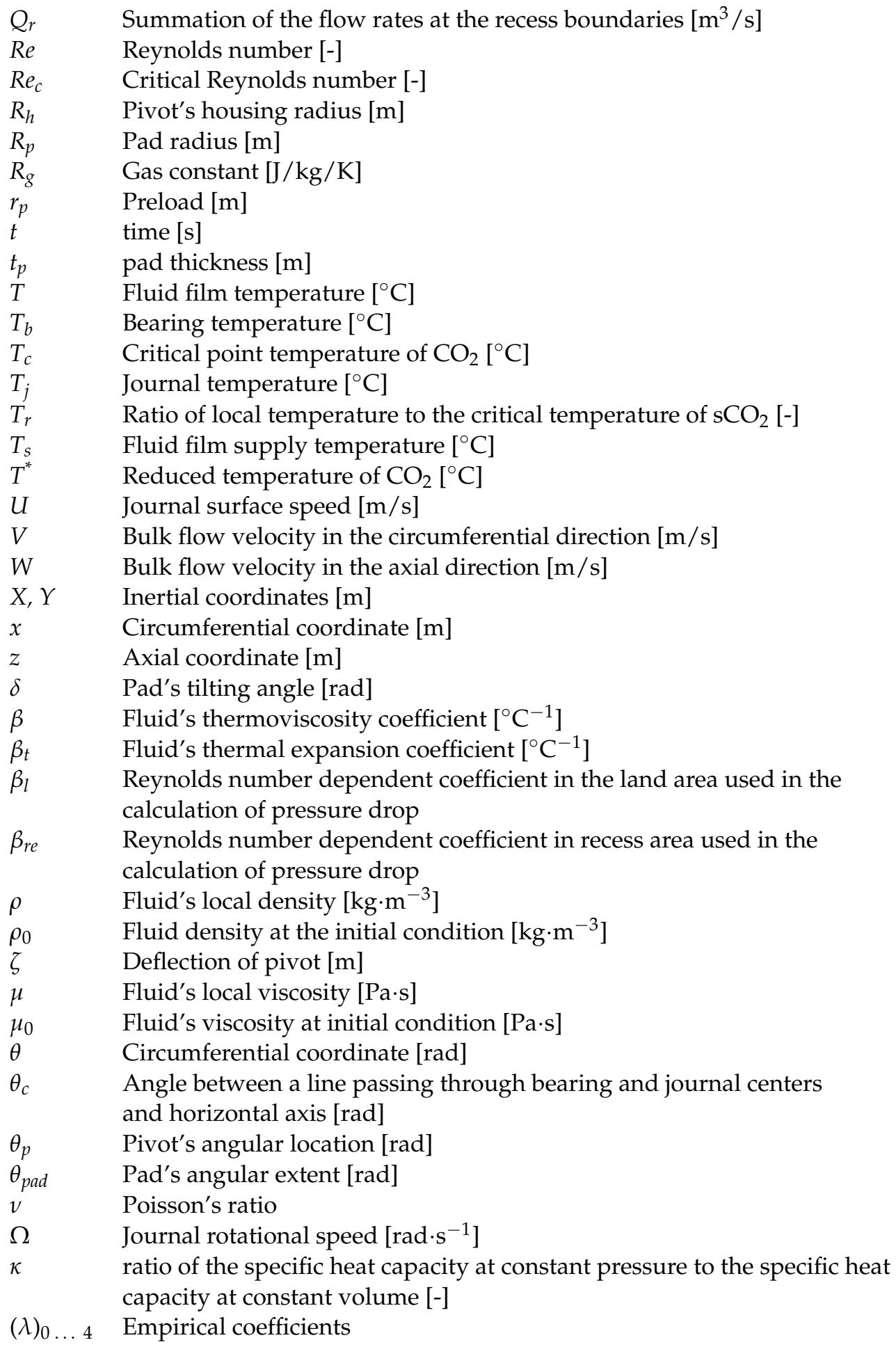

\section{Appendix A. Pad Tilting Angle, Pivot Deflection, and Pivot Maximum Stress}

Figure A1 shows the pad tilting angle versus supply pressure for each pad. The null pressure indicates hydrodynamic lubrication. As the supply pressure increases from 10 to $20 \mathrm{MPa}$, the pad tilt angle decreases, except for pad 3. 


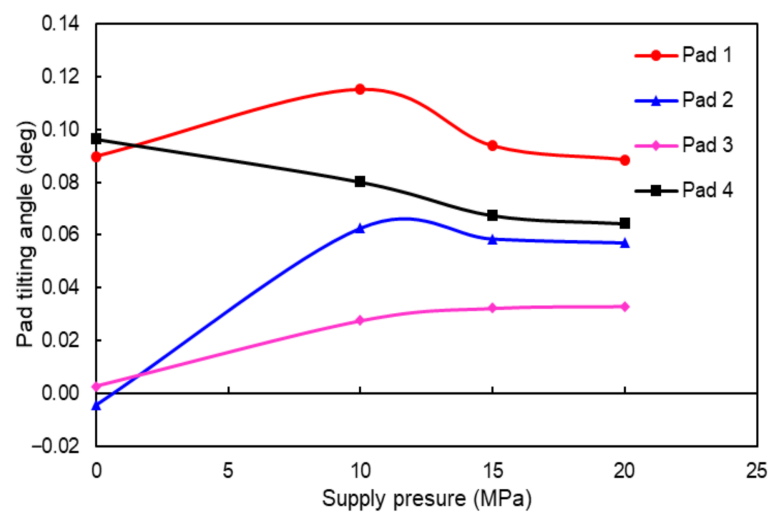

Figure A1. Pad tilt angle vs. supply pressure. Rotor speed $=60 \mathrm{krpm}$, and static load $=100 \mathrm{~N}$.

Pivot deflection, stiffness, and stress based on the Hertzian contact theory:

The pivot model in Refs. [28-30] calculates the pivot deflection in this study. In addition, Equation (A1) calculates the pivot maximum stress $\sigma_{\max }$ based on Hertzian contact theory [40].

$$
\sigma_{\max }=0.798 \sqrt{\frac{E\left(D_{h}-D_{p}\right) F_{p}}{2\left(1-v^{2}\right) D_{h} D_{p}}}
$$

where $F_{p}, v, E, D_{h}$, and $D_{p}$ are the force concentrated on the pivot, Poisson's ratio, Young's modulus, housing diameter, and pivot diameter, respectively. During the design, the maximum stress under given pivot forces must be calculated to avoid surface damage.

Figure A2 shows the pivot deflection and maximum pivot stress versus supply pressure for each pivot at a rotor speed of $60 \mathrm{krpm}$ with a static load of $100 \mathrm{~N}$. As the supply pressure increases, the pivot deflection increases. The loaded pads (pads 3 and 4) have pivot deflections larger than those for the unloaded pads (pads 1 and 2). Akin to pivot deflections, the maximum pivot stress increases with an increase in the supply pressure, and the highest pivot stress occurs at the loaded pads (pads 3 and 4). The highest value of the pivot stress for a supply pressure of $20 \mathrm{MPa}$ is $6.4 \mathrm{MPa}$, which is well below the yield strength $(240 \mathrm{MPa})$ of structural steel, indicating a high design safety factor.
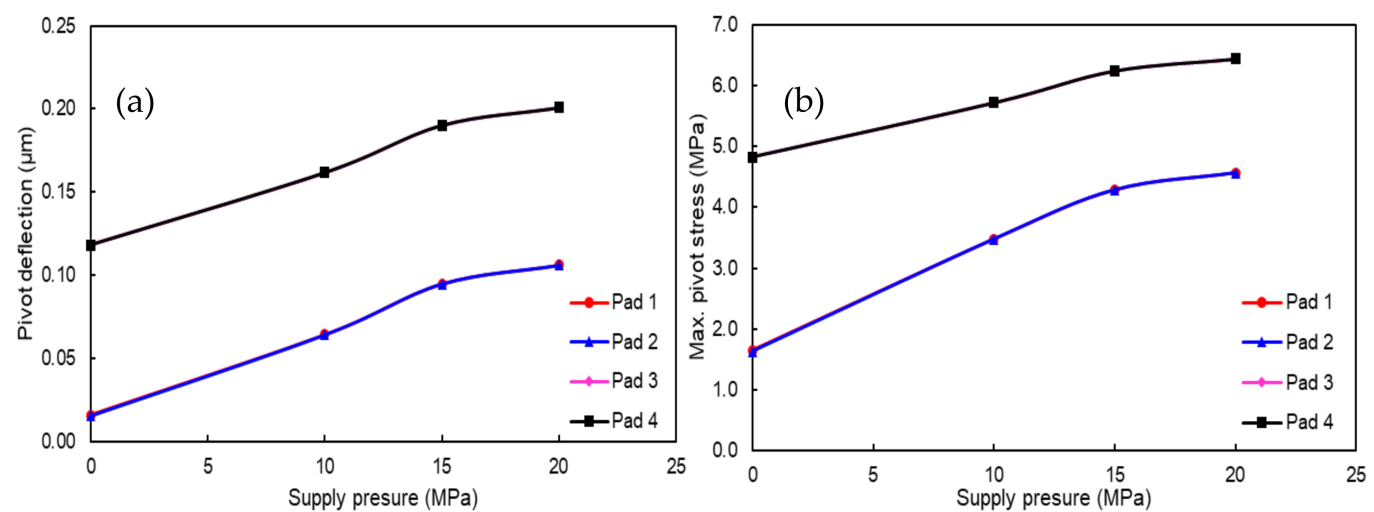

Figure A2. (a) Pivot deflection and (b) maximum stress vs. supply pressure. Rotor speed $=60 \mathrm{krpm}$, and static load $=100 \mathrm{~N}$.

\section{References}

1. Brun, K.; Friedman, P.; Dennis, R. Fundamentals and Applications of Supercritical Carbon Dioxide $\left(\mathrm{SCO}_{2}\right)$ Based Power Cycles; Brun, K., Friedman, P., Richard, D., Eds.; Woodhead Publishing: Sawston, UK, 2017; ISBN 9781845697693.

2. Wright, S.A.; Radel, R.F.; Vernon, M.E.; Rochau, G.E.; Pickard, P.S. Operation and Analysis of a Supercritical $\mathrm{CO}_{2}$ Brayton Cycle; Sandia National Laboratory: Albuquerque, NM, USA, 2010.

3. Conboy, T.; Wright, S.; Pasch, J.; Fleming, D.; Rochau, G.; Fuller, R. Performance characteristics of an operating supercritical CO 2 Brayton cycle. J. Eng. Gas Turbines Power 2012, 134, 111703. [CrossRef] 
4. Turchi, C.S.; Ma, Z.; Neises, T.W.; Wagner, M.J. Thermodynamic study of advanced supercritical carbon dioxide power cycles for concentrating solar power systems. J. Sol. Energy Eng. 2013, 135, 041007. [CrossRef]

5. Dostal, V.; Hejzlar, P.; Driscoll, M.J. High-performance supercritical carbon dioxide cycle for next-generation nuclear reactors. Nucl. Technol. 2006, 154, 265-282. [CrossRef]

6. Uusitalo, A.; Ameli, A.; Turunen-Saaresti, T. Thermodynamic and turbomachinery design analysis of supercritical Brayton cycles for exhaust gas heat recovery. Energy 2019, 167, 60-79. [CrossRef]

7. Cho, J.; Choi, M.; Baik, Y.-J.; Lee, G.; Ra, H.-S.; Kim, B.; Kim, M. Development of the turbomachinery for the supercritical carbon dioxide power cycle. Int. J. Energy Res. 2016, 40, 587-599. [CrossRef]

8. Cho, J.; Shin, H.; Ra, H.S.; Lee, G.; Roh, C.; Lee, B.; Baik, Y.J. Development of the supercritical carbon dioxide power cycle experimental loop in KIER. In Proceedings of the ASME Turbo Expo 2016: Turbomachinery Technical Conference and Exposition, Seoul, Korea, 13-17 June 2016; Volume 9, pp. 1-8.

9. Ahn, Y.; Lee, J.; Kim, S.G.; Lee, J.I.; Cha, J.E. The design study of supercritical carbon dioxide integral experimental loop. In Proceedings of the ASME Turbo Expo 2013: Turbine Technical Conference and Exposition, San Antonio, TX, USA, 3-7 June 2013; pp. 1-7.

10. Utamura, M.; Hasuike, H.; Yamamoto, T. Demonstration test plant of closed cycle gas turbine with supercritical $\mathrm{CO}_{2}$ as working fluid. Strojarstvo 2010, 52, 459-465.

11. Conboy, T.M. Real-gas effects in foil thrust bearings operating in the turbulent regime. J. Tribol. 2013, 135, 031703. [CrossRef]

12. Lemmon, E.W.; McLinden, M.O.; Huber, M.L. NIST Reference Fluid Thermodynamic and Transport Properties-REFPROP. Available online: https:/ / webbook.nist.gov/chemistry/fluid/\# (accessed on 1 January 2019).

13. Qin, K.; Jahn, I.; Gollan, R.; Jacobs, P. Development of a computational tool to simulate foil bearings for supercritical $\mathrm{CO}_{2} \mathrm{cycles}$. Eng. Gas Turbines Power 2016, 138, 092503. [CrossRef]

14. Qin, K.; Jahn, I.H.; Jacobs, P.A. Effect of operating conditions on the elastohydrodynamic performance of foil thrust bearings for supercritical $\mathrm{CO}_{2}$ cycles. J. Eng. Gas Turbines Power 2017, 139, 042505. [CrossRef]

15. Dousti, S.; Allaire, P. A compressible hydrodynamic analysis of journal bearings lubricated with supercritical carbon dioxide. In Proceedings of the 5th International Supercritical $\mathrm{CO}_{2}$ Power Cycles Symposium, San Antonio, TX, USA, 29-31 March 2016; pp. 1-18.

16. Heshmat, H.; Walton II, J.F.; Cordova, J.L. Technology readiness of 5th and 6th generation compliant foil bearing for $10 \mathrm{MWE}$ $\mathrm{s}-\mathrm{CO}_{2}$ turbomachinery systems. In Proceedings of the 6th International Supercritical $\mathrm{CO}_{2}$ Power Cycles Symposium, Pittsburgh, PA, USA, 27-29 March 2018; pp. 1-29.

17. Dimond, T.; Younan, A.; Allaire, P. Journal bearing lubrication using $\mathrm{sCO}_{2}-\mathrm{A}$ theoretical study. In Proceedings of the 2nd International Supercritical $\mathrm{CO}_{2}$ Power Cycles Symposium, Troy, NY, USA, 29-30 April 2009.

18. $\mathrm{Xu}, \mathrm{F}$; Kim, D. Three-dimensional turbulent thermo-elastohydrodynamic analyses of hybrid thrust foil bearings using real gas model. In Proceedings of the ASME Turbo Expo 2016: Turbomachinery Technical Conference and Exposition, Seoul, Korea, 13-17 June 2016; Volume 7B-2016, pp. 1-10.

19. Preuss, J.L. Application of hydrostatic bearings in supercritical $\mathrm{CO}_{2}$ turbomachinery. In Proceedings of the 5th International Supercritical $\mathrm{CO}_{2}$ Power Cycles Symposium, San Antonio, TX, USA; 2016; pp. 1-10.

20. San Andrés, L.; Childs, D.W. Angled Injection-Hydrostatic Bearings Comparison to Test Results. J. Tribol. 1997, 119, $179-187$. [CrossRef]

21. Bi, C.; Han, D.; Yang, J. The frequency perturbation method for predicting dynamic coefficients of supercritical carbon dioxide lubricated bearings. Tribol. Int. 2020, 146, 106256. [CrossRef]

22. Kim, D.; Baik, S.; Lee, J.I. Instability Study of Magnetic Journal Bearing under S-CO $\mathrm{CO}_{2}$ Condition. Appl. Sci. 2021, $11,3491$. [CrossRef]

23. San Andrés, L. Hybrid-flexure pivot-tilting pad gas bearings: Analysis and experimental validation. J. Tribol. 2006, 128, 551-558. [CrossRef]

24. San Andrés, L.; Ryu, K. Flexure pivot tilting pad hybrid gas bearings: Operation with worn clearances and two load-pad configurations. J. Eng. Gas Turbines Power 2008, 130, 042506. [CrossRef]

25. Hirs, G.G. A Bulk-flow theory for turbulence in lubricant films. J. Lubr. Technol. 1973, 137-145. [CrossRef]

26. Okabe, E.P.; Cavalca, K.L. Rotordynamic analysis of systems with a non-linear model of tilting pad bearings including turbulence effects. Nonlinear Dyn. 2009, 57, 481-495. [CrossRef]

27. Orcutt, F.K. The steady-state and dynamic characteristics of the tilting-pad journal bearing in laminar and turbulent flow regimes. J. Lubr. Technol. 1967, 89, 392-400. [CrossRef]

28. Mehdi, S.M.; Jang, K.E.; Kim, T.H. Effects of pivot design on performance of tilting pad journal bearings. Tribol. Int. 2018, 119, 175-189. [CrossRef]

29. Lee, T.W.; Kim, T.H. Finite element analysis of pivot stiffness for tilting pad bearings and comparison to Hertzian contact model calculations. J. Korean Soc. Tribol. Lubr. Eng. 2014, 30, 205-211. [CrossRef]

30. Choi, T.G.; Kim, T.H. Analysis of Tilting Pad Journal Bearings Considering Pivot Stiffness. J. Korean Soc. Tribol. Lubr. Eng. 2014, 30, 77-85.

31. Brian Rowe, W. FiMeche Hydrostatic, Aerostatic and Hybrid Bearing Design, 1st ed.; Elsevier Inc.: London, UK, 2012 ; ISBN 9780123969941.

32. Constantinescu, V.N.; Galetuse, S. Pressure Drop Due To Inertia Forces in Step Bearings. J. Lubr. Technol. 1975, 167-174. [CrossRef] 
33. Bou-Said, B.; Chaomleffel, J.P. Hybrid Journal Bearings: Theoretical and Experimental Results. J. Tribol. 1989, 111, $265-269$. [CrossRef]

34. San Andrés, L. Notes10: Thermohydrodynamic Bulk-Flow Model in Thin Film Lubrication. Available online: http://phn.tamu. edu/me626 (accessed on 20 August 2016).

35. Wang, Z.; Sun, B.; Yan, L. Improved density correlation for supercritical CO $\mathrm{CO}_{2}$. Chem. Eng. Technol. 2015, 38, 75-84. [CrossRef]

36. Fenghour, A.; Wakeham, W.A.; Vesovic, V. The viscosity of carbon dioxide. J. Phys. Chem. Ref. Data 1998, 27, 31-44. [CrossRef]

37. Liu, Z.; Wang, Y.; Cai, L.; Zhao, Y.; Cheng, Q.; Dong, X. A review of hydrostatic bearing system: Researches and applications. Adv. Mech. Eng. 2017, 9, 1687814017730536. [CrossRef]

38. Balbahadur, A.C.; Kirk, R. Part I-Theoretical Model for a Synchronous Thermal Instability Operating in Overhung Rotors. Int. J. Rotating Mach. 2004, 10, 469-475. [CrossRef]

39. Chaomleffel, J.P.; Nicolas, D. Experimental investigation of hybrid journal bearings. Tribol. Int. 1986, 19, 253-259. [CrossRef]

40. Young, W.C.; Budnyas, R.G. Roark's Formulas for Stress and Strain, 7th ed.; McGraw-Hill: New York, NY, USA, 2002; ISBN 0-07-072542-X. 